\title{
Accessibility and transport infrastructure improvement assessment: The role of borders and multilateral resistance
}

\author{
María Henar Salas-Olmedo, Patricia García, Javier Gutiérrez
}

Keywords:

Accessibility

Transport infrastructure impacts

Border effect

Spatial Multilateral Resistance European

Union

\begin{abstract}
A B S T R A C T
The market potential indicator is a commonly used tool in transport planning for evaluating the potential economic effects derived from improvements in transport infrastructures. The general assumption is that exports from a given region will rise with increased accessibility, thus benefiting economic activities. However, the specification of the market potential model is typically very simple and ignores both the impact of competing rivals and the role of international borders, which leads to unrealistic results. Spatial interaction models on bilateral trade have already proved that international trade is affected by multilateral resistance, borders, adjacency, language or currency. Nevertheless, apart from some recent analyses that simply calibrate the distance decay parameter from trade datasets, these variables have hardly been integrated into research on market potential. This paper sets out to demonstrate that more realistic results are obtained by calibrating the distance-decay parameter and introducing the impact of competing rivals and border effects into the market potential formulation. The proposed model is then applied to the assessment of the accessibility impacts of new road transport infrastructure in the European Union between 2001 and 2012, which shows that the greatest improvements in accessibility were experienced by peripheral countries with high road infrastructure investment.
\end{abstract}

\section{Introduction}

The concept of accessibility established by Harris (1954) and Hansen (1959) refers to the measurement of opportunities available to a particular place. Seen from this viewpoint, it is accessibility, rather than transport infrastructure, that is a key factor in understanding regional development, both existing and potential (Wegener, 1995), based on consideration of the relative position of a particular place in relation to the whole system. Different specifications of potential accessibility have been used to estimate the number of opportunities available to a certain place. These potential accessibility indicators assume that the number of trade opportunities increases with the size of each destination and decreases with the distance between origin and destination.

Knowing the potential accessibility to markets, and where potential markets are located, is of great help to policy makers for designing regional development strategies. Similarly, transport planners, both at regional level and above, are interested in knowing which markets are less accessible as a result of insufficient or inefficient transport networks. In addition, market potential figures serve as an assessment tool for checking the impact of transport measures on the potential development of regions, a good example being the pan-European analysis by Spiekermann and Wegener (2006). 
In the case of potential accessibility to international markets, the effect of borders on trade has to be considered in order to obtain accurate estimations of the number of opportunities that are reachable from a particular location in an international environment. There is a broad literature on assessment of the magnitude of such border effects, especially since the study by McCallum (1995), who found that Canadian provinces trade 22 more times between themselves than with a US state, distance and other factors being equal.

In addition to the role of international borders and other proxies for cultural closeness, there is a need for estimations of market potential to integrate the relative position of each particular place in relation to the whole system. In this way, the number of opportunities reachable from a particular place can be calibrated in relation to the size of all markets and the distance between them. This issue of so-called multilateral resistance was addressed by Anderson and van Wincoop (2003).

While special care is taken to produce homogeneous results throughout the European territory, apart from size and distance between origin and destination other factors affecting potential accessibility are rarely considered. In contrast to the above-mentioned findings on the effects of borders on trade and the role of competing rivals, border effects and multilateral resistance are usually ignored in most research on potential accessibility.

This is evidenced by the absence of any consideration of this issue in the extended review by Rietveld and Bruinsma (1998), the brief mention it gets in the review by Spiekermann and Neubauer (2002), and the abundance of models assuming that opportunities are equally accessible in a national and an international environment (ESPON, 2015, 2007; Schürmann and Talaat, 2002; Stelder, 2014). Concern about the role of competing rival countries was only linked to the estimation of the border effect after it was addressed by Anderson and van Wincoop (2003), but was usually simplified into remoteness indices or fixed effects. Some exceptions are found in the work by Head and Mayer (2004) and Huber et al. (2006), who introduced the border effect and other impedances to international trade. However, their estimation of multilateral resistance was based simply on fixed effects and they failed to give a realistic measurement of the distance between origin and destination.

Most research on the role of borders and other factors influencing international trade has paid little attention to the way distance is measured and integrated in the model. Although there was great interest in defining the effects of borders or competing rivals, distance was typically measured without considering real connectivity through the transport network. Most of the discussion focused on the bias arising from the way domestic versus international distances were estimated. Based on the discussion started by Wei (1996), Head and Mayer (2002) provided a methodology to measure both international and domestic distances homogeneously, which was subsequently used by Chen (2004) and more recently by Mayer and Zignago (2011) and by Bruyne et al. (2013). However, none of them addressed the impact of approximating transport costs through a realistic measurement of distance.

This is surprising, given the globalisation trend in which real transport costs are less directly linked to physical distance not to mention the simplistic Euclidean or great circle distance. Still, most applications use a simple distance conceptualisation, such as great circle distance (Anderson and van Wincoop, 2003; Bacaria-Colom et al., 2013; Behrens et al., 2012; Bruyne et al., 2013; Bussière et al., 2005; Chen, 2004; Head and Mayer, 2004, 2002; Wei, 1996) or area-based functions (Helliwell and Verdier, 2001; Helliwell, 2002; Nitsch, 2000). A few exceptions are found in American literature with the use of kilometres along the road network according to a road atlas (Wolf, 2000, 1997) or the reported distance gathered from a survey (Hillberry and Hummels, 2003).

Building upon homogeneous methodology to estimate both domestic and international measurements, Salas-Olmedo et al. (2014) provide an in-depth analysis on the influence of different distance conceptualisations on the estimation of border effects. According to them, travel time is considered to be a realistic approach to generalised transport costs. Both of these more realistic and complex distance measurements suggest an underestimation of previous home bias estimations derived from Euclidean distances.

Our interest lies in assessing the economic impact of transport infrastructure in Europe by integrating the abovementioned three lines of research: potential accessibility, border effects and multilateral resistance. We introduce two subsequent improvements to the market potential model. First, the role of all competing rivals is introduced with a new variable measuring multilateral resistance. The next step is to test and calibrate this and other significant variables, such as borders, adjacency or language, using a trade gravity model. The calibrated parameters of the significant variables are then included in the market potential specification in order to analyse the impact of new infrastructures on accessibility. Unlike previous papers, which overestimate the international impact of new infrastructures, we obtain more realistic results, since the role of competing countries and the effect of borders is taken into consideration.

The structure of the paper is as follows: Sections 2 and 3 set out the specific background on previous research related to market potential, and to the border effect and multilateral resistance, respectively. Section 4 details the methodology and includes a final subsection describing the data sources. The main results of this research are presented in Section 5 , with subsections devoted to a deeper understanding of the role of competing rivals, calibration of the model and the market potential distribution at national and regional level in 2012, as well as the changes brought about by investment in transport infrastructure since 2001. The last section of the paper consists of conclusions and final remarks.

\section{Measuring accessibility: the market potential indicator}

Accessibility is a blurred concept that has been defined in many ways. In-depth reviews and typologies can be found in Rietveld and Bruinsma (1998) and Geurs and van Wee (2004). In this study, we are interested in the seminal definition pro- 
vided by Harris (1954) and Hansen (1959), who focus their interest on measuring the potential for interaction. From the perspective of economic activities, the potential for interaction can be measured as the size of the markets that can be accessed from a particular location through a transport network, bearing in mind that the chances to trade with a particular market decrease with distance. The larger the size of surrounding markets, and the smaller the distance to them, the higher the economic potential of a place.

The market potential indicator has been used extensively in transport studies to measure the impact of new transport infrastructures (for example, Condeço-Melhorado et al., 2011; Dundon-Smith and Gibb, 1994; Gutiérrez, 2001; Gutiérrez et al., 2011; López et al., 2009; Martin et al., 2010; Spence and Linneker, 1994; Stepniak and Rosik, 2013). The assumption underlying the use of this model is that regions with better access to markets have a higher probability of being economically successful (Wegener and Bökemann, 1998). In transport planning this indicator measures the market potential of each place in each of the scenarios considered (with and without project) and the changes in market potential caused by the new infrastructure. The general function of the market potential is shown in Eq. (1) (Krugman, 1992):

$$
M_{i}=\sum_{j} Y_{j} g\left(D_{j k}\right)
$$

where the accessibility of region $i\left(M_{i}\right)$ is a function of the sum of the size of destinations $\left(Y_{j}\right)$ and the distance between origin and destination $\left(D_{j k}\right)$. The distance is usually measured in terms of kilometres, travel time or transport costs. The $g$ parameter needs to be calibrated in order to estimate the declining function of distance. Some studies do not calibrate this parameter but use exponent 1 or 2 (Bruinsma and Rietveld, 1998; Gutiérrez, 2001; Holl, 2011, 2007; Keeble et al., 1988; Lopez, 2005; Tagai et al., 2008). Others use the exponential function with a variety of ad hoc parameters (see Rosik et al., 2015 for a summary). Fortunately, the growing availability of origin-destination matrices facilitates the calibration of this distance decay parameter, using gravity models in order to obtain more realistic results (see, for example, Condeço-Melhorado et al., 2011; Reggiani and Bucci, 2008; Reggiani et al., 2011). It has been demonstrated that this exponent has a dramatic influence on accessibility results (Condeço-Melhorado et al., 2013).

Because the effects of new infrastructures may be not confined to the countries where they are constructed, but spill over their limits into other countries as well, the border effect and other factors influencing international trade should also be considered. In fact, not considering such factors should be reflected in an overestimation of international spillovers. These factors have been widely included in gravity trade models, but surprisingly they have been ignored in most accessibility studies at international level. The following section examines in more detail the role of borders and competing rivals present within the system.

\section{The border effect and multilateral resistance: the role of competing rivals}

The seminal study by McCallum (1995) sparked a growing interest in disentangling the behaviour of international trade. The focus was initially on estimating home bias due to the border effect, using of a gravity model in which trade was a function of the size of the origin and destination markets and the distance between them, and a new binary variable that distinguished domestic from international trade between US states and Canadian provinces. McCallum estimated that international trade between a Canadian province and a US state is 22 times lower than trade between two Canadian provinces, distance and other factors being equal.

Several papers applied McCallum's gravity equation, incorporating a series of new variables such as adjacency, common language or shared currency. For example, Wei (1996) estimated the border effect in several sets of countries with different models. He found that controlling for remoteness, adjacency and language reduces the border effect from 9.7 to 2.6 in OECD countries. Further research has also downgraded McCallum's estimation to lower values, reporting that European countries typically trade within their own borders between 2 and 10 times more than with other European countries (Chen, 2004; Nitsch, 2000; Wei, 1996).

According to Salas-Olmedo et al. (2014), border effect estimations seem to be strongly affected both by the Rotterdam effect ${ }^{1}$ and by the distance metric (i.e. Euclidean vs. travel time). Once the Rotterdam effect was removed and distance modelled as travel time or generalised transport costs in a set of 18 European countries, the authors estimated that these countries trade 15 times less between each other than within their own borders.

The gravity model received critics because of its weak theoretical foundations and due to the influence of the size of the study areas over the results obtained. Yet, empirical-based gravity equations are useful as descriptive tools that allow the analysis of changes over time, for example before and after the extension of the $\mathrm{EU}$, or before and during the economic crisis.

Anderson and van Wincoop (2003) raised a crucial issue relating to the role of the relative position of each country within the whole system. The authors criticised the traditional gravity model because it did not take the role of competing rivals into consideration. In other words, McCallum's and similar gravity equations establish that exports from country A to country B are a function of the size of A and B and the distance and barriers between them, but do not take into account

\footnotetext{
${ }^{1}$ The Rotterdam effect has been recognized as affecting European trade statistics (Commission, 2006, p. 22). This effect reflects the impact of triangular trade on export figures: export figures from a country (A) to another country (B) may be overestimated if they include goods that are being forwarded from another country (C) via country (A) (ONS, 2009).
} 
their relative position in a system of $n$ countries. Anderson and van Wincoop (2004) consider three alternatives for introducing this so-called multilateral resistance to trade: (a) the introduction of a function of bilateral distances and a dummy variable for international borders (Anderson and van Wincoop, 2003, 2001; Minondo, 2005, 2007); (b) the introduction of region-specific dummies (Bacaria-Colom et al., 2013; Behncke, 2013; Bussière et al., 2005; Feenstra, 2004); and (c) the use of price indices (Behrens et al., 2012; Bergstrand, 1985; Egger and Larch, 2011; Head and Mayer, 2000; Serlenga and Shin, 2013).

Remoteness indices have come in for considerable criticism because the only factor they assess is distance and they frequently lack significance (Head and Mayer, 2014). Anderson and van Wincoop (2001, 2003) modified this approach by incorporating the border effect into the equation and linking it to the theory, although the approach was still strongly econometric. The fixed effects approach was mostly criticised for being artificial and requiring excessive computing resources for large study areas where the symmetric assumption does not apply (Minondo, 2005). The main criticism of the price indices approach relates to the lack of observable data and disconnection from distance and other factors affecting trade (Bacaria-Colom et al., 2013; Bruyne et al., 2013; Feenstra, 2004).

Within this framework, our research builds upon the highly accepted approach developed by Anderson and van Wincoop in 2003. They introduced multilateral resistance by estimating a function of the observable trade costs and a dummy variable replacing the border effect with its opposite, thereby accounting for home bias due to the presence of borders. All bilateral resistances are included in the equation, thus linking their solution to the theory. This approach was followed in subsequent research (Bruyne et al., 2013; Minondo, 2005, 2007).

The main difference between our approach and the Anderson and van Wincoop $(2001,2003)$ specification lies in the full consideration that our approach gives to the spatial perspective. We propose a new indicator of Spatial Multilateral Resistance (SMLR) that relates the distance and market size of all potential markets that interact with each bilateral relationship (see further details in Section 4.3).

Our gravity-based approach for estimating multilateral resistance to potential trade allows for integration of the role of international borders and is consistent with the market potential gravity model. Our specification is based fully on observable data and is easy to compute, regardless of the number of locations involved. Integrating and calibrating the role of competing rivals and the effects of borders and distance decay with real data creates a richer perspective than the fixed effect or price indices approach.

\section{Methodology and data}

\subsection{The two step model}

In order to obtain a more realistic formulation of the market potential indicator, we propose in this paper a methodology that considers not only the mass of the destination countries and the distance to them, but also the role of competing countries (multilateral resistance) and other barriers to trade (such as border effect, adjacency and language). These variables are calibrated using a gravity trade model and then, if significant, introduced into the market potential specification. In this sense, we are not trying to find the best trade model specification but a simple formulation consistent with market potential. We therefore calibrated and assessed the role of each of these variables in international trade by solving a gravity equation using Ordinary Least Squares (OLS). Formula (2) contains the simplest model to which we added the new variables on a oneto-one basis.

$$
\ln X_{i j}=\beta_{0}+\beta_{1} \ln Y_{i}+\beta_{2} \ln Y_{j}+\beta_{3} \ln D_{i j}+\varepsilon_{i j}
$$

where $X_{i j}$ is the bilateral trade from country $i$ to country $j ; Y$ is the size of the market, and $D$ is the distance between $i$ and $j$. In this equation, $\beta_{3}$ indicates the distance decay parameter.

The second step in our methodology is to introduce the distance decay parameter as well as other variables and their coefficients that are found to be significant in the market potential specification. The initial market potential equation (formula (1)) will then be modified accordingly as in formula (3):

$$
P_{i}=\sum\left(\frac{Y_{j}}{D_{i j}^{\beta_{3}}}\right) \times \operatorname{var}_{x}^{a} \times \operatorname{var}_{y}^{b} \times \cdots
$$

where $P_{i}$ is the market potential of country $i, Y_{j}$ is the size of destination $j, D_{i j}$ is the distance between country $i$ and country $j$, $\beta_{3}$ is the distance decay parameter from formula (6), and $v a r_{x}^{a}$ and so on represent the value and parameters of the significant variables as extracted from the gravity Eq. (2).

As in previous studies, our formulation needs a single distance decay value for results across study areas to be comparable. Similarly, the border effect and any other coefficient also need to be globally calibrated. In addition, we aim to calculate the part of the market potential that is a consequence of direct investment in transport infrastructure. To do this, we backdated distance measurements to a previous year and kept the rest of the variables and all the coefficients in current time. The difference between current and distance-backdated market potential reveals the impact of transport investment on the market potential of European countries and regions. 
Similarly, we applied country-level gravity trade calibration coefficients to the market potential calculation at regional level in order to detect spatial patterns within the countries and potential differences across international borders.

The great differences in the sizes of European regions bring the Modifiable Areal Unit Problem (MAUP) to the fore. The ESPON report on the MAUP (ESPON, 2006) offers a variety of solutions to minimise the impact of the MAUP on results produced on a regional scale. One solution is to use a combination of NUTS 2 and 3 regions, which is particularly useful for our study since it respects international boundaries. Consequently, we updated the NUTS2 \& NUTS3 unit combination provided in the EU-LUPA project with the new NUTS 2010 version for which most data is available for different years.

\subsection{Calculation of bilateral and internal travel times}

Region-to-region travel time was computed using a commercial GIS (ArcGIS 10.1) that includes specific network simulation routines for calculating minimum paths through the network. Formulas (4) and (5) were used to obtain the travel time between the exporter country $i$ and the importer country $j$ as the GDP-weighted average of travel time between all regions in the country of origin $i$ and all regions in the destination country (see Head and Mayer, 2002; Chen, 2004):

$$
\begin{aligned}
D_{i j} & =\frac{\sum\left(D_{m_{i} m_{j}} \times S_{m_{i}} \times S_{m_{j}}\right)}{\sum\left(S_{m_{i}} \times S_{m_{j}}\right)} \\
S_{m} & =\left(\frac{G D P_{m}}{G D P}\right)
\end{aligned}
$$

where $D_{i j}$ is the travel time between county $i$ and country $j, D_{\text {mimj }}$ is the travel time between region $m$ in country $i$ and region $m$ in country $j, G D P_{m}$ is the GDP of region $m$ and GDP is the total GDP.

To estimate the internal travel time of each region, an average internal travel distance was calculated according to Rich (1978):

$$
D_{a a}=\frac{1}{2} \sqrt{\frac{S_{a}}{\pi}}
$$

where $D_{a a}$ is the internal distance (in $\mathrm{km}$ ) of region $a$, and $S_{a}$ is its area (in square kilometres).

A congestion effect was considered within regions according to their population density. The region with the lowest population density was assigned a speed of $80 \mathrm{~km}$ per hour, whereas the region with the highest value was assigned a speed of $20 \mathrm{~km}$ per hour (Gutiérrez et al., 2011). The internal travel time within each region was then calculated using estimated internal distances and speeds. This is a critical issue in the calculation of the potential market indicator, since self-potential (internal accessibility) can represent an important part of the total potential market of the region, particularly in metropolitan regions.

\subsection{Spatial Multilateral Resistance (SMLR)}

The market potential of each country is usually calculated by considering its relationship to each of the destination countries in terms of mass and distance and ignoring the role of the rest of the countries in each of these relationships. According to the spatial nature of the market potential model, we propose the formulation of a variable that captures the role of competing rivals, i.e. the resistance from third countries that a country has to overcome in each bilateral relationship. In our research we estimated this new variable (Spatial Multilateral Resistance - SMLR) by using a measurement that relates the GDP of the competing rivals for a particular destination and the distance between the competing rivals and the destination, using the following formula (7):

$$
S M L R_{i j}=\frac{\left[\left(\sum_{k} \frac{Y_{k}}{D_{k j}}\right)-\frac{Y_{i}}{D_{i j}}\right]}{\frac{\sum_{n, m}\left[\left(\sum_{k} \frac{Y_{k}}{D_{k m}}\right)-\frac{Y_{n}}{D_{n m}}\right]}{N}}
$$

where $Y_{i}$ and $Y_{j}$ represent the size of the market of origin and destination respectively, in this case in terms of GDP, $D_{i j}$ is the distance between origin $i$ and destination $j$, in our case represented in minutes of travel time computed as explained in Section 4.2, $k$ and $n$ are each of all the origins, and $m$ is each of all the destinations. The numerator is calculated as the total sum of the GDP of all destination countries for the given destination country $j$, divided by the distance separating each pair, excluding from the total sum the part corresponding from destination $j$ to the initial origin $i$. However, the term corresponding to the own country $j$ is included, thereby taking into account each destination's own resistance to trade. The denominator is the average of the total sum indicated in the numerator in order to obtain a homogeneous standardised SMLR value in relative terms.

The higher the value of $S M L R_{i j}$, the more difficult it is to export from country $i$ to country $j$, due to the high competency of all other countries, including $j$ 's own power to enter into that market. This value is unique for each relationship and involves all other countries considered in the system according to their bilateral distances. The term is also included when estimating 

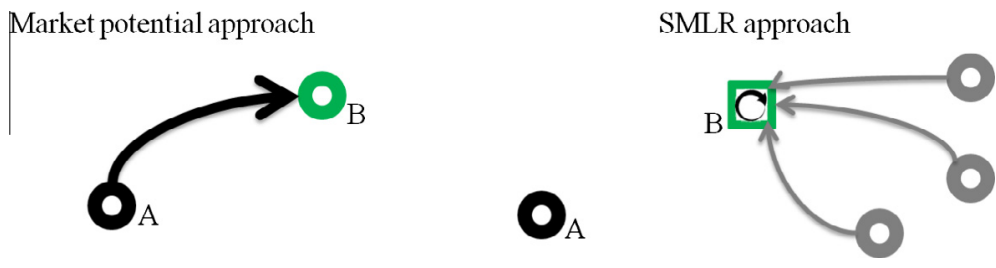

Fig. 1. The role of the relative position of each country within the whole system.

domestic trade, since the capacity of competing rivals to enter the internal market is also taken into account. By introducing this new variable (SMLR) in our model we aim to estimate how much less a country trades with another country due to the presence of competing rivals.

This is illustrated in Fig. 1, where the diagram on the left represents the traditional model in which the focus is exclusively on each bilateral relationship. Conversely, the diagram on the right reflects the influence the system has on that particular bilateral relationship: clients in the destination market $\left(\right.$ green $^{2}$ ) have multiple providers; therefore, only a share of the opportunities are available to the particular origin in this bilateral relationship (black).

Using the bilateral relationship of trade from Austria to France as an example, our proposal consists of calibrating the role of all other countries with respect to the capacity of Austria to export to France. The numerator in formula ( 7 ) therefore equals the weighted sum of the GDP of each other country, divided by the distance between each of these countries and France. This value is then divided by the average of the values for doing the same operation, taking all the other countries as the origin.

\subsection{Other barriers to trade}

Other barriers to trade were built as dummy variables. In order to estimate the border effect, the no-home variable was assigned 1 for bilateral relationships and 0 for domestic trade. Other variables, such as the lack of a common language, the inexistence of common borders (i.e. adjacency) or the use of a different currency, were built in the same way.

\subsection{Data sources}

GDP and distance data are necessary for both the trade model and the calculation of market potential. The GDP and population data at regional level were taken from EUROSTAT for the year 2011. Travel time between all origins and destinations was calculated using the Database of European Roads (Stelder, 2013). This contains data showing the historical development of the road and ferry network every 10 years since 1957 until 2012. ${ }^{3}$ Although a fixed speed had already been estimated for each of the three road classes, we substituted these general values for heavy-goods-vehicle (HGV) specific type speeds. ${ }^{4}$ Because of the lack of connectivity with Cyprus and Malta in Stelder's road database, these countries were removed from the analysis. In addition, these countries, together with Luxembourg, are too small to implement homogeneous intra- and international distance measurements so the analysis was finally performed on the remaining EU24 countries. ${ }^{5}$

Regarding international trade, we analysed Transtools, Worldnet and ETIS (base and plus versions) estimated databases at regional level and found strong incongruence when these were compared to country-level data available in various European and worldwide databases. Consequently, we focused on country-level international trade databases, including the OECD, Comext and the World Input/Output Database (WIOD, Timmer et al., 2015). From these, we chose WIOD because, unlike the other datasets, it provides both bilateral and domestic trade values. In this way, we were able to overcome one of the most controversial issues in previous studies using trade matrices: the rough estimation of domestic trade as the difference between national production and all exports (as in Wei, 1996; Nitsch, 2000; Head and Mayer, 2000; Chen, 2004), which overestimates the proportion of exports, is substituted by data provided by the WIOD project, derived from the sound analysis of a combination of different datasets. Internal trade figures are consistent with individual figures available in specific national studies, thus the above-mentioned Rotterdam effect seems to be minimised.

\footnotetext{
${ }^{2}$ For interpretation of color in Fig. 1, the reader is referred to the web version of this article.

${ }^{3}$ Further information on the network and the process to create the historical database can be found in Stelder (2013) (http://www.regroningen.nl/ stelder/doc/final_report_roads_2013.pdf). To the best of our knowledge, this is the only historical European road database which is available as open data. Although there are some inconsistencies in the network, probably due to road re-coding processes, it is still useful to test our methodology and to provide an insight of the European situation.

4 We applied an average speed for maximum-weighted-trucks of $75 \mathrm{~km} / \mathrm{h}$ (according to DAF, n.d., p. 7) on main roads (class 2 ) and upgraded the speed on highways (class 1) to $90 \mathrm{~km} / \mathrm{h}$, which is the average maximum speed allowed for HGV on highways in EU countries. We then downgraded the speed to $60 \mathrm{~km} / \mathrm{h}$ for secondary roads (class 3 ).

${ }^{5}$ Note that Croatia was not part of the EU at the time of the analysis (2012).
} 


\section{Results}

\subsection{Calculating SMLR: some preliminary outputs}

The traditional barriers to trade (borders, adjacency, language, etc.) do not present any complexity when it comes to applying the methodology for their calculation, since they can be treated as dummy variables. Nevertheless, the SMLR variable requires greater attention owing to the newness of its formulation. Our proposal for introducing competition among rivals is to consider a measurement that relates the GDP of countries sharing a potential market and their distance to it in relative terms. The calculation must be standardised and homogeneous. The result is a univocal value of SMLR for each bilateral relationship in a non-symmetrical matrix.

Before introducing the border effect and other trade barriers, we should assess the difficulty of access to each market due to the competence of the rest of the countries in the system by looking at bilateral relationships. For each country (line series), Fig. 2 shows which countries (radial axis) find it easier to enter its market. Countries that find it easy to enter the market of a particular country make the line of that particular country shrink towards the centre when its axis is crossed. For example, in the case of Belgium (the outermost line), Germany and France are the countries that can access its market most easily. The average size of each line series indicates the overall pressure from neighbouring countries to enter a particular country. In this case, Belgium is the country whose neighbours generate the highest pressure for a third country to enter its market. This happens because Belgium is a small country which has large economies within a small distance (i.e. Germany, France, the Netherlands and the United Kingdom). In contrast, Finland, which has a relatively small economic size and a large physical size obtains the lowest values in SMLR. This is because Finland's neighbours are few, farther away and relatively small, economically speaking, therefore it is not very difficult for a distant country to enter its market. When the axis is looked at transversally, Germany seems to be the country that shows less SMLR values in most other countries. France is in a very competitive position with respect to its potential exports to Spain; the same is true for Spain to Portugal and the UK to Ireland.

This analysis allows verification of the adjustment of the SMLR variable to the EU scenario, guaranteeing an alignment between the perception of reality and the proposed formulation. Exploration of these preliminary results shows consistent outcomes and an absence of anomalies in the behaviour of the variable itself.

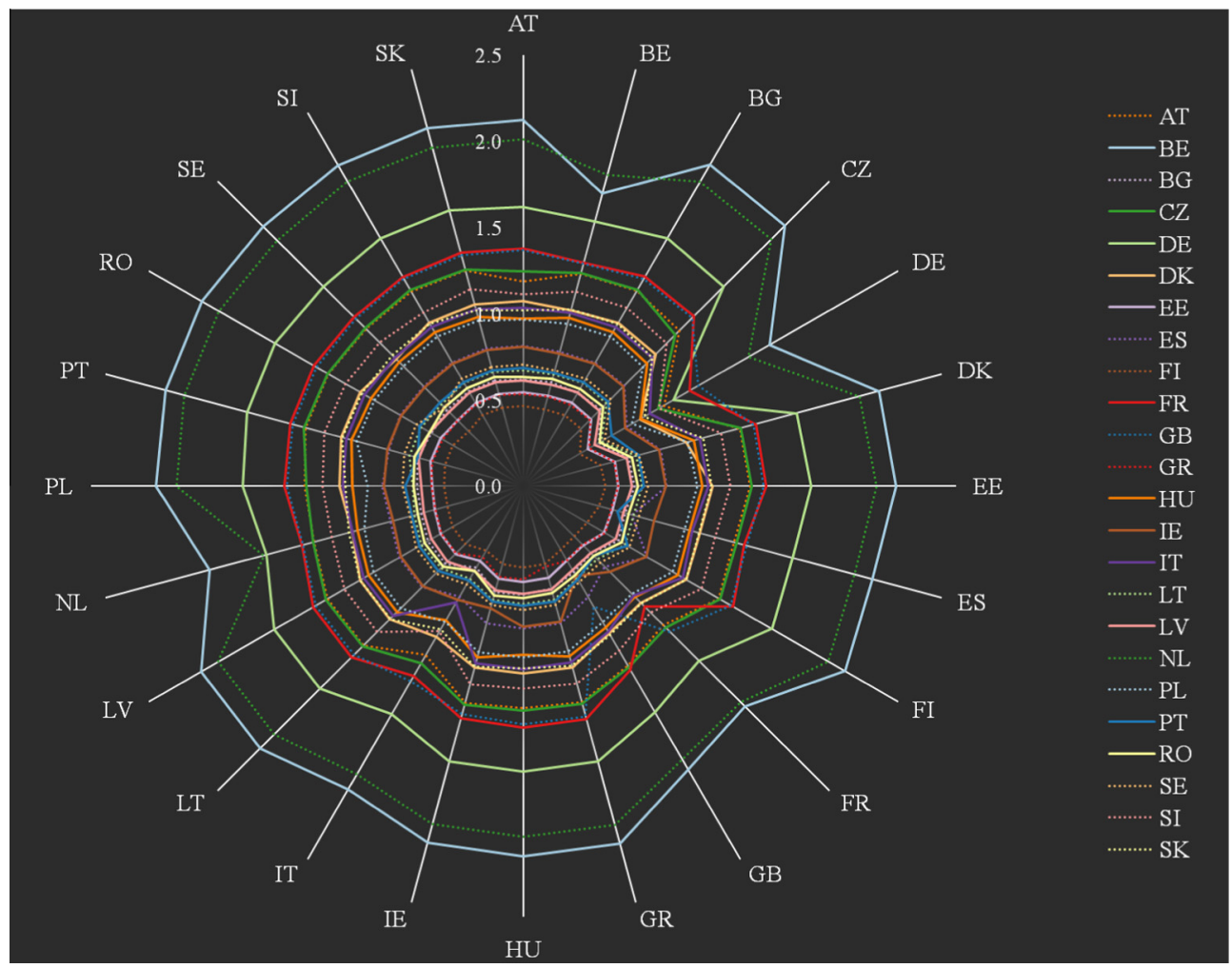

Fig. 2. Spatial Multilateral Resistance (SMLR) at the country level. Note: Country codes: AT (Austria), BE (Belgium), BG (Bulgaria), CZ (Czech Republic), DE (Germany), DK (Denmark), EE (Estonia), ES (Spain), FI (Finland), FR (France), GB (Great Britain), GR (Greece), HU (Hungary), IE (Ireland), IT (Italy), LT (Lithuania), LV (Latvia), NL (Netherlands), PL (Poland), PT (Portugal), RO (Romania), SE (Sweden), SI (Slovenia), SK (Slovakia). Source: Authors' own elaboration from WIOD, EUROSTAT, Database of European roads 1957-2012 and GISCO. 
Table 1

Pearson's correlation matrix between variables. Source: Authors' calculations from WIOD, EUROSTAT, Database of European roads $1957-2012$ and GISCO.

\begin{tabular}{|c|c|c|c|c|c|c|c|c|c|}
\hline & Ln Exports & Ln GDP $i$ & Ln $\mathrm{GDP}_{j}$ & Ln travel time & Ln SMLR & No Home & No adj. & Dif. language & Dif. currency \\
\hline Ln Exports & 1 & & & & & & & & \\
\hline Ln GDP & $.564^{* * *}$ & 1 & & & & & & & \\
\hline Ln $\mathrm{GDP}_{\mathrm{j}}$ & $.511^{* * *}$ & .000 & 1 & & & & & & \\
\hline Ln travel time & $-.551^{* *}$ & -.004 & -.004 & 1 & & & & & \\
\hline Ln SMLR & $.222^{* * *}$ & $-.121^{* *}$ & $.533^{* *}$ & $-.233^{* *}$ & 1 & & & & \\
\hline No Home & $-.395^{* * *}$ & .000 & .000 & $.564^{* *}$ & .054 & 1 & & & \\
\hline No adj. & $-.308^{* *}$ & -.064 & -.064 & $.479^{* *}$ & $-.087^{*}$ & -.072 & 1 & & \\
\hline Dif. language & $-.260^{* *}$ & $-.106^{*}$ & $-.106^{*}$ & $.330^{* * *}$ & $-.144^{* *}$ & -.052 & $.626^{* *}$ & 1 & \\
\hline Dif. currency & $-.149^{* * *}$ & $-.150^{* *}$ & $-.150^{* * *}$ & .022 & -.078 & $.107^{*}$ & .058 & $.100^{*}$ & 1 \\
\hline
\end{tabular}

Significant at the 0.01 level (bilateral).

Significant at the 0.05 level (bilateral).

\subsection{Calibrating the model}

The model was calibrated with the use of the gravity model and data at country level. Dependent and candidate independent variables and their correlations are shown in Table 1, which enables the signs and degree of relationships and potential multicollinearity issues to be explored. As expected, the countries' exports are positively correlated with their own GDP and the GDP of the destination, and are negatively affected by travel time and other barriers to travel. Surprisingly, the correlation between SMLR and exports is positive in this initial bivariate approach. Multicollinearity issues can be discarded, since all coefficients are below the 0.7 threshold.

These variables were introduced in the basic model in a one-by-one process in order to test the significance of the variables and find the best fit model (see Table 2). Model 0 represents the traditional distance decay calibration, in which neither the role of competing rivals, borders nor other barriers to trade are considered. The coefficient of distance decay ( -1.887 ) indicates that distance (measured as travel time) makes trade decay more sharply than the estimations of some authors (distance decay $=-1$ according to Keeble et al. (1988) and Holl (2007)), and less than the estimations of others, such as Tagai et al. (2008), who estimated distance decay equal to -2 . This therefore supports the need to calibrate it.

Calibrating distance decay as a mere function of the masses at origin and destination might not be sufficient to model the relationships as part of a system. We introduced the new SMLR variable in Model I, which shows the role and impact of competing rivals. All variables in this model are significant and both the adjusted $R^{2}$ and AICc indicate a better fit than Model 0 . The capacity to export is influenced by the relative position of the exporter within the system, which in turn seems to affect distance decay. Once the SMLR is introduced into the model with the rest of the variables, it gives the expected sign (positive).

In addition, we were interested in knowing whether borders still matter in international trade within a virtually borderless framework such as the EU. Model II evidences that borders still influence international trade by dividing their value by 2.8 (exp. 1.03) when compared to domestic trade, other things being equal. Interestingly, the coefficient that captures the border effect (No Home) also catches part of the distance decay (Travel Time) and the role of competing rivals (SMLR). In this model, all variables are significant at the 0.01 level and both the adjusted $R^{2}$ and AICc confirm the better fit of the model. As in previous models, the variance inflation factor (VIF) is low in all cases, which allows multicollinearity issues to be discarded.

We proceeded to introduce the rest of the candidate variables to check for their significance. We found that they are not significant at the 0.01 level and therefore chose Model II (formula (8)) to calibrate the parameters of the proposed market potential specification.

$$
\ln X_{i j}=\beta_{0}+\beta_{1} \ln Y_{i}+\beta_{2} \ln Y_{j}+\beta_{3} \ln D_{i j}+\beta_{4} \ln S M L R_{i j}+\beta_{5} \text { border }+\varepsilon_{i j}
$$

where $S M L R_{i j}$ is the Spatial Multilateral Resistance term, border is the dummy variable reflecting the border effect and the other terms are already known. In this equation, $\beta_{3}$ indicates the distance-decay parameter, $\beta_{4}$ the SMLR parameter and the exponent of $\beta_{5}$ is the number of times that a country trades less with a foreign destination than with a national one, other things being equal.

\subsection{Applying the (proposed) market potential model}

According to our spatial interaction model (formula (8)), the market potential formulation was modified to suit the parameters that resulted significant, i.e. distance decay, SMLR and border effect coefficients, resulting in formula (9):

$$
P_{i}= \begin{cases}\sum \frac{Y_{j} / S M L R_{i j}^{\beta_{4}}}{t_{i j}^{-\beta_{3}}}, & i=j \\ \sum \frac{Y_{j} / S M L R_{i j}^{\beta_{4}} e^{\beta_{5}}}{t_{i j}^{-\beta_{3}}}, & i \neq j\end{cases}
$$


Table 2

Comparison of gravity models (OLS). Source: Authors' calculations from WIOD, EUROSTAT, Database of European roads 1957-2012 and GISCO.

\begin{tabular}{|c|c|c|c|c|c|c|c|c|c|c|c|c|c|c|c|c|c|c|}
\hline \multirow[b]{2}{*}{ Variables } & \multicolumn{3}{|l|}{ Model 0} & \multicolumn{3}{|l|}{ Model I } & \multicolumn{3}{|l|}{ Model II } & \multicolumn{3}{|l|}{ Model III } & \multicolumn{3}{|l|}{ Model IV } & \multicolumn{3}{|l|}{ Model V } \\
\hline & $\beta$ & Sig. & VIF & $\beta$ & Sig. & VIF & $\beta$ & Sig. & VIF & $\beta$ & Sig. & VIF & $\beta$ & Sig. & VIF & $\beta$ & Sig. & VIF \\
\hline Intercept & -12.590 & 0.000 & & -14.712 & 0.000 & & -14.604 & 0.000 & & -14.600 & 0.000 & & -14.723 & 0.000 & & -15.097 & 0.000 & \\
\hline Ln $\mathrm{GDP}_{\mathrm{i}}$ & 0.925 & 0.000 & 1.000 & 0.891 & 0.000 & 1.083 & 0.896 & 0.000 & 1.025 & 0.896 & 0.000 & 1.027 & 0.898 & 0.000 & 1.037 & 0.905 & 0.000 & 1.052 \\
\hline $\operatorname{Ln} \mathrm{GDP}_{j}$ & 0.838 & 0.000 & 1.000 & 0.986 & 0.000 & 1.023 & 0.964 & 0.000 & 1.474 & 0.963 & 0.000 & 1.537 & 0.967 & 0.000 & 1.498 & 0.970 & 0.000 & 1.488 \\
\hline Ln $D_{i j}$ (travel time) & -1.887 & 0.000 & 1.000 & -2.021 & 0.000 & 1.438 & -1.830 & 0.000 & 1.714 & -1.825 & 0.000 & 3.020 & -1.852 & 0.000 & 2.103 & -1.821 & 0.000 & 1.721 \\
\hline Ln SMLR & & & & -0.951 & 0.000 & 1.545 & -0.809 & 0.000 & 1.674 & -0.807 & 0.000 & 1.776 & -0.814 & 0.000 & 1.680 & -0.798 & 0.000 & 1.678 \\
\hline No Home & & & & & & & -1.030 & 0.000 & 1.590 & -1.042 & 0.000 & 2.166 & -0.981 & 0.000 & 1.762 & -1.089 & 0.000 & 1.616 \\
\hline No adjacency & & & & & & & & & & -0.014 & 0.919 & 1.794 & & & & & & \\
\hline No language & & & & & & & & & & & & & 0.113 & 0.445 & 1.277 & & & \\
\hline No currency & & & & & & & & & & & & & & & & 0.160 & 0.017 & 1.065 \\
\hline Exp. No Home & & & & & & & 2.801 & & & 2.834 & & & 2.667 & & & 2.972 & & \\
\hline$R^{2}$ & 0.879 & & & 0.897 & & & 0.902 & & & 0.902 & & & 0.902 & & & 0.903 & & \\
\hline Adj. $R^{2}$ & 0.878 & & & 0.896 & & & 0.901 & & & 0.901 & & & 0.901 & & & 0.902 & & \\
\hline F-stat & 1383.62 & & & 1245.87 & & & 1049.69 & & & 873.22 & & & 874.20 & & & 883.04 & & \\
\hline $\mathrm{AICC}$ & 1411.67 & & & 1319.29 & & & 1293.58 & & & 1295.63 & & & 1295.05 & & & 1289.82 & & \\
\hline
\end{tabular}


Table 3

Market potential values: effects of the introduction of the different parameters of model II (results per country). Source: Authors' calculations from WIOD, EUROSTAT, Database of European roads 1957-2012 and GISCO.

\begin{tabular}{|c|c|c|c|c|c|c|c|c|}
\hline Country & $P_{i}$ with $\mathrm{DD}=1$ & $\begin{array}{l}P_{i} \text { with } \\
\mathrm{DD}=1.887\end{array}$ & $P_{i}$ with DD & $\begin{array}{l}P_{i} \text { with DD and } \\
\text { SMLR }\end{array}$ & $\begin{array}{l}P_{i} \text { with DD, SMLR and } \\
\text { No Home }\end{array}$ & $\begin{array}{l}\text { Loss due to } \\
\text { DD }\end{array}$ & $\begin{array}{l}\text { Diff due to } \\
\text { SMLR }\end{array}$ & $\begin{array}{l}\text { Loss due to No } \\
\text { Home }\end{array}$ \\
\hline AT & 20494543618 & 89126947 & 125180344 & 103320070 & 52752757 & -99.389 & -17.463 & -48.942 \\
\hline $\mathrm{BE}$ & 33677268163 & 326773159 & 431127138 & 293357873 & 189686499 & -98.720 & -31.956 & -35.340 \\
\hline BG & 9999811953 & 22197587 & 32475349 & 32494786 & 15214811 & -99.675 & 0.060 & -53.178 \\
\hline $\mathrm{CZ}$ & 20630977742 & 92560621 & 129646558 & 103565032 & 49001129 & -99.372 & -20.117 & -52.686 \\
\hline $\mathrm{DE}$ & 26011079070 & 135512196 & 188747569 & 185231573 & 134121574 & -99.274 & -1.863 & -27.592 \\
\hline DK & 17119124818 & 70832609 & 99164798 & 86148089 & 52933792 & -99.421 & -13.126 & -38.555 \\
\hline EE & 8739720519 & 18819001 & 27299391 & 29088759 & 15727413 & -99.688 & 6.555 & -45.933 \\
\hline ES & 12960785226 & 36299954 & 52511861 & 56933488 & 39625668 & -99.595 & 8.420 & -30.400 \\
\hline $\mathrm{FI}$ & 7425787944 & 15754838 & 22862654 & 30938098 & 23348004 & -99.692 & 35.322 & -24.533 \\
\hline FR & 21969251130 & 91503090 & 129450284 & 120956847 & 79932557 & -99.411 & -6.561 & -33.916 \\
\hline GB & 21701612987 & 119589689 & 165012064 & 178233240 & 150754969 & -99.240 & 8.012 & -15.417 \\
\hline GR & 8607768745 & 20213311 & 29191931 & 36311481 & 26641285 & -99.661 & 24.389 & -26.631 \\
\hline $\mathrm{HU}$ & 16206957368 & 62289949 & 87655150 & 76965326 & 39580301 & -99.459 & -12.195 & -48.574 \\
\hline IE & 12849431932 & 48025649 & 67185043 & 65728099 & 45265191 & -99.477 & -2.169 & -31.133 \\
\hline IT & 16704869130 & 56125330 & 80399190 & 81481161 & 56988139 & -99.519 & 1.346 & -30.060 \\
\hline LT & 10791419152 & 26379986 & 38248329 & 36201704 & 17761366 & -99.646 & -5.351 & -50.938 \\
\hline LV & 9850524465 & 23032796 & 33349177 & 33284905 & 16933570 & -99.661 & -0.193 & -49.125 \\
\hline $\mathrm{NL}$ & 31908098695 & 289477547 & 384563457 & 277044588 & 191124229 & -98.795 & -27.959 & -31.013 \\
\hline PL & 15710867944 & 52774480 & 75399781 & 65823195 & 36312091 & -99.520 & -12.701 & -44.834 \\
\hline PT & 10898156421 & 31383574 & 44880266 & 49054086 & 30286673 & -99.588 & 9.300 & -38.259 \\
\hline RO & 10323248926 & 23137346 & 33889512 & 33064462 & 17378743 & -99.672 & -2.435 & -47.440 \\
\hline $\mathrm{SE}$ & 11269415525 & 27673098 & 40328302 & 39502076 & 23818046 & -99.642 & -2.049 & -39.704 \\
\hline SI & 18717124982 & 77881170 & 109210629 & 91144824 & 41130649 & -99.417 & -16.542 & -54.873 \\
\hline SK & 17062336338 & 65039806 & 91959973 & 77609666 & 33510970 & -99.461 & -15.605 & -56.821 \\
\hline Average & 16317924283 & 75933488.94 & 104989115 & 90978476 & 57492934 & -99.46 & -3.95 & -39.83 \\
\hline STD & 6967605639 & 77328863.93 & 101891491 & 71919265 & 52025221 & 0.25 & 14.91 & 10.99 \\
\hline $\mathrm{CV}$ & 42.7 & 101.8 & 97 & 79 & 90.5 & -0.2 & -377.2 & -27.6 \\
\hline
\end{tabular}

Table 4

Correlation coefficients between the actual international trade matrix and market potential matrices (showing the potential that each country received from each of the other countries).

\begin{tabular}{lll}
\hline Market potential specification & Pearson's correlation coefficient & Sig. \\
\hline Non-calibrated market potential: Distance decay =1 & 0.466 \\
Model 0: Calibrating distance decay without trade barriers =1.887 & 0.788 & 0.021 \\
Model II: Calibrating distance decay and trade barriers: Introducing calibrated & 0.931 & 0.000 \\
$\quad$ distance decay (1.830), calibrated SMLR $(0.809)$ and calibrated border effect $(2.801)$ & & 0.000 \\
\hline
\end{tabular}

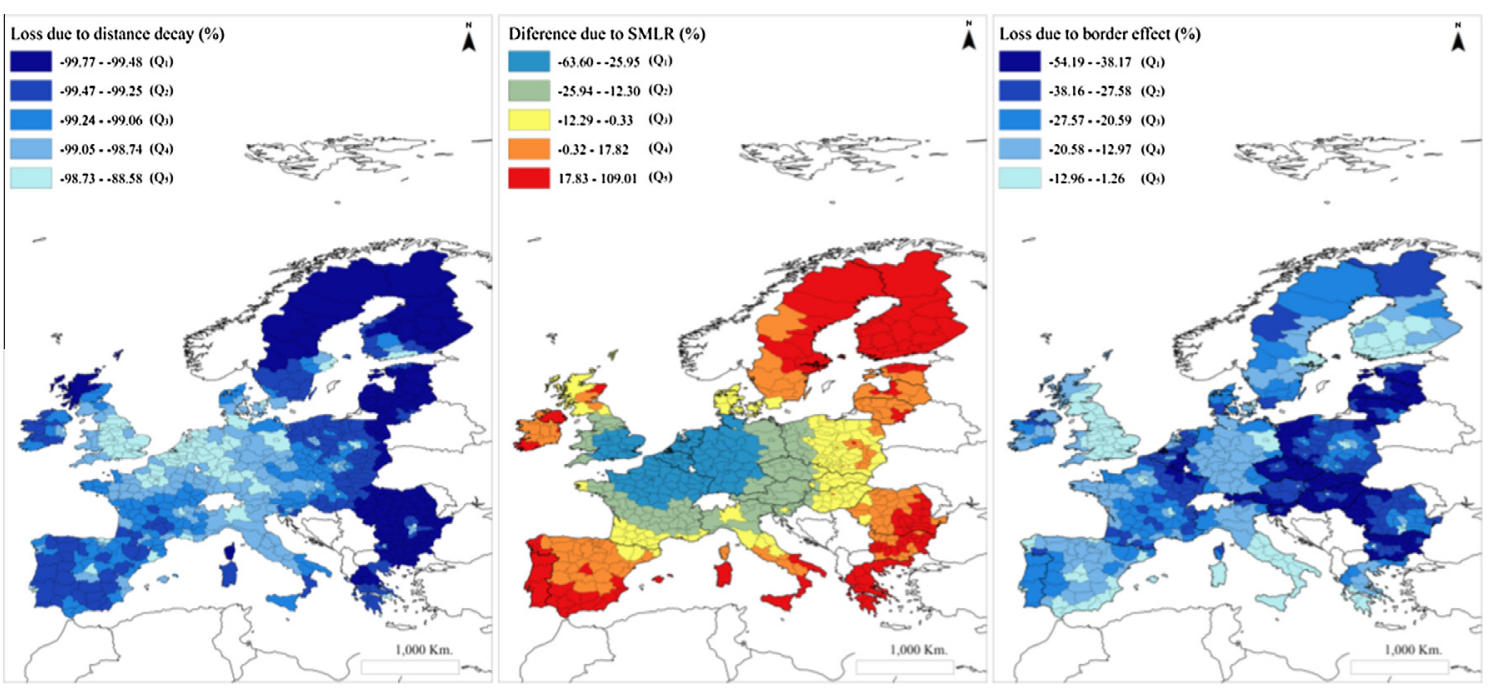

Fig. 3. Changes in market potential when each properly calibrated factor is introduced, NUTs $2 / 3$, 2012. Source: Authors' calculations from WIOD, EUROSTAT, Database of European roads 1957-2012 and GISCO. 

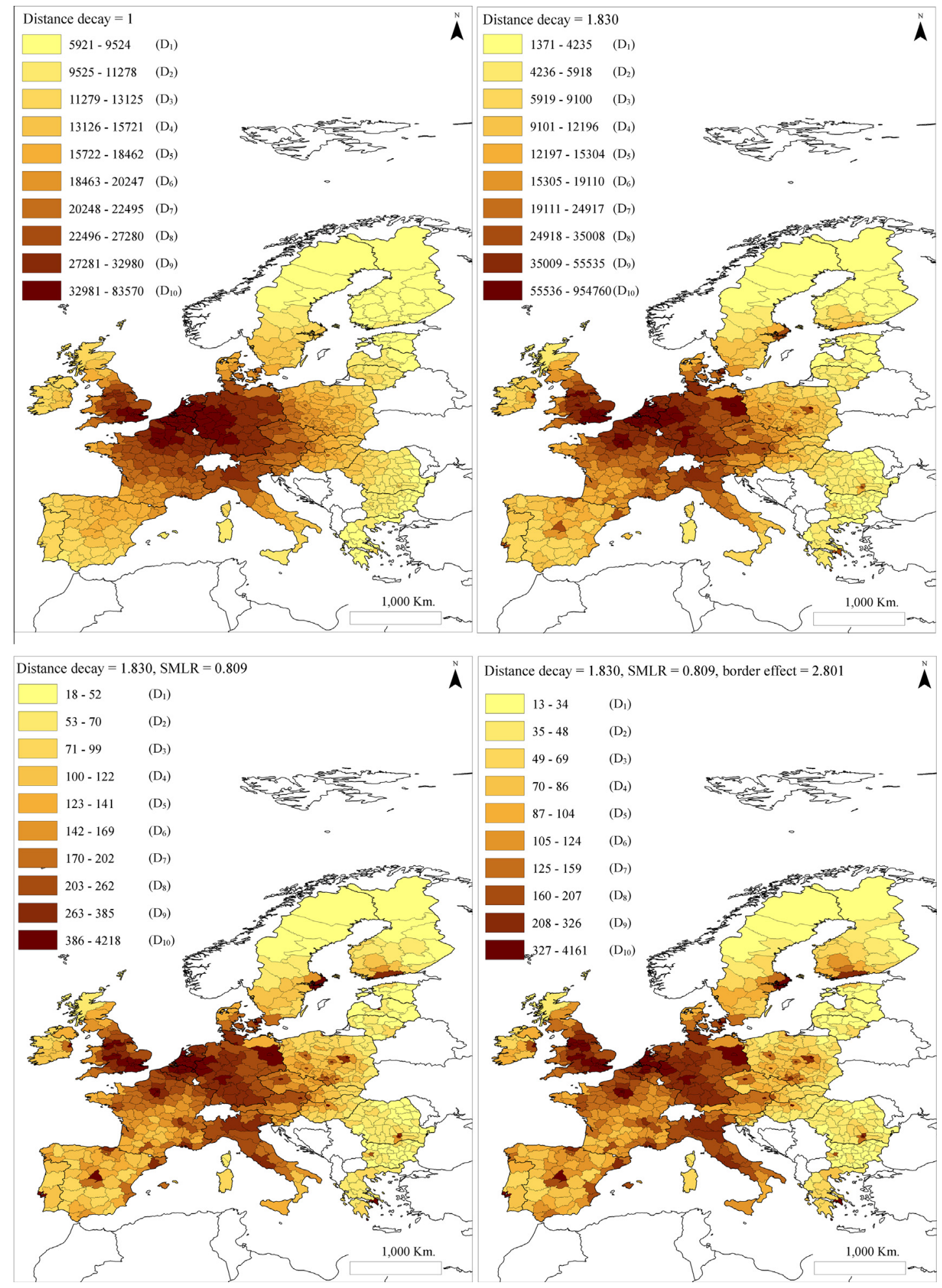

Fig. 4. Market potential values according to different formulations: results per NUTS $2 / 3$ level (in millions of market potential units). Source: Authors' calculations from WIOD, EUROSTAT, Database of European roads 1957-2012 and GISCO. 


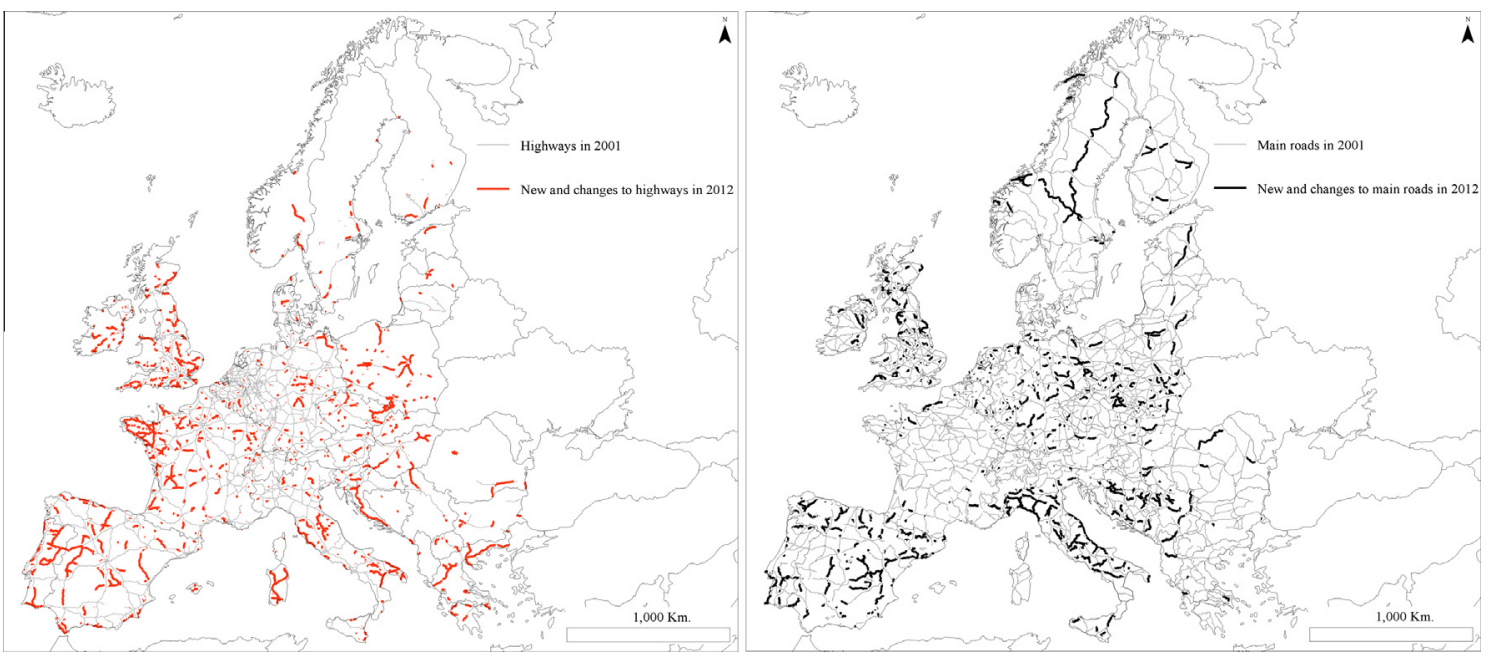

Fig. 5. Changes in the road network in Europe, 2001-2012. Source: Database of European roads 1957-2012.

Table 5

Results of the calibration model in 2001 and 2012.

\begin{tabular}{|c|c|c|c|c|c|c|}
\hline \multirow[b]{2}{*}{ Variables } & \multicolumn{3}{|c|}{ Model II 2001} & \multicolumn{3}{|c|}{ Model II 2012} \\
\hline & $\beta$ & Sig. & VIF & $\beta$ & Sig. & VIF \\
\hline Intercept & -12.391 & 0.000 & & -14.604 & 0.000 & \\
\hline $\mathrm{GDP}_{\mathrm{i}}$ & 0.88 & 0.000 & 1.027 & 0.896 & 0.000 & 1.03 \\
\hline $\mathrm{GDP}_{\mathrm{j}}$ & 0.864 & 0.000 & 1.547 & 0.964 & 0.000 & 1.47 \\
\hline$D_{i j}$ (travel time) & -1.562 & 0.000 & 1.706 & -1.83 & 0.000 & 1.71 \\
\hline No Home & -1.89 & 0.000 & 1.576 & -1.03 & 0.000 & 1.59 \\
\hline SMLR & -0.541 & 0.000 & 1.749 & -0.809 & 0.000 & 1.67 \\
\hline Border effect (Exp No Home) & 6.622 & & & 2.801 & & \\
\hline$R^{2}$ & 0.896 & & & 0.902 & & \\
\hline Adj. $R^{2}$ & 0.895 & & & 0.901 & & \\
\hline$F$-stat & 977.25 & 0.000 & & 1049.7 & 0.000 & \\
\hline AICc & 1387.78 & & & 1293.6 & & \\
\hline
\end{tabular}

Results at country level (Table 3) reveal the overestimation of market potential values computed with traditional specifications. The fact that distance decay is calibrated means there is a dramatic reduction in the market potential values of all countries, which is more intense in peripheral countries than in those at the centre. The effect of introducing the SMLR variable reflects the different impact of competing rivals according to the relative location of each country. In this case, Belgium and the Netherlands are most affected owing to their proximity to large markets, while peripheral countries (especially Finland and Greece) benefit from their isolation from big economies, thus preserving their self-potential (internal market). On the other hand, the effect of borders is visible in all countries, with a clearly larger negative impact in Eastern countries and a reduced impact in larger economies like Great Britain or Germany. The coefficient of variation proves that differences in market potential among countries are emphasised when the proposed market potential specification is considered (42.7 in the traditional specification and 90.5 in the proposed one).

Table 4 shows that, as expected, controlling for distance decay, SMLR and border effect increases the correlation coefficient between market potential and trade, leading to more realistic market potential estimations than assuming a distance decay value of 1 or calibrating distance decay without considering the rest of the system and other trade barriers.

At regional level (Fig. 3), the distance decay value also shows that shorter distances are more relevant than those suggested by the traditional model (distance decay $=1$ ). Consequently, peripheral regions, which are subject to trade over longer distances, are more highly penalised than central ones. When introducing the SMLR, peripheral regions increase their MP values because there are fewer competing rivals in their surroundings. The border effect has a strong impact on border regions. It is particularly interesting to see areas in which this impact is different on different sides of the border, particularly in the case of the Ireland/UK border and that of Germany with the countries surrounding it.

A deeper analysis of regional market potential results (Fig. 4) reveals that once distance decay is calibrated, internal differences emerge within each country, highlighting differences between dense and sparsely populated regions and providing more details on the general core-periphery pattern. Introducing the SMLR enhances these differences in peripheral countries. The border effect enhances the unbalanced border separating Eastern and Western Europe. 
Table 6

Difference in market potential between 2001 and 2011 due to differences in the transport network, by country. Source: Authors' calculations.

\begin{tabular}{|c|c|c|c|c|c|c|c|c|}
\hline \multirow[t]{2}{*}{ Country } & \multicolumn{4}{|c|}{$\begin{array}{l}\text { Traditional model (distance decay }=1 \text {, no SMLR and no border } \\
\text { effect) }\end{array}$} & \multicolumn{4}{|c|}{$\begin{array}{l}\text { Proposed market potential model }(\text { distance decay }=1.83 \text {, } \\
\text { SMLR }=0.809 \text {, border effect }=2.801 \text { ) }\end{array}$} \\
\hline & $\begin{array}{l}\text { Market potential } \\
2012 \text { with } 2001 \\
\text { network }\end{array}$ & $\begin{array}{l}\text { Market potential } \\
2012 \text { with } 2012 \\
\text { network }\end{array}$ & $\begin{array}{l}\text { Differences } \\
\text { (abs.) }\end{array}$ & $\begin{array}{l}\text { Differences } \\
(\%)\end{array}$ & $\begin{array}{l}\text { Market potential } \\
2012 \text { with } 2001 \\
\text { network }\end{array}$ & $\begin{array}{l}\text { Market potential } \\
2012 \text { with } 2012 \\
\text { network }\end{array}$ & $\begin{array}{l}\text { Differences } \\
\text { (abs.) }\end{array}$ & $\begin{array}{l}\text { Differences } \\
(\%)\end{array}$ \\
\hline Austria & 19997449267 & 20494543618 & 497094351 & 2.5 & 50559265 & 52752757 & 2193493 & 4.3 \\
\hline Belgium & 32947017189 & 33677268163 & 730250974 & 2.2 & 181597126 & 189686499 & 8089373 & 4.5 \\
\hline Bulgaria & 9603157894 & 9999811953 & 396654059 & 4.1 & 13835643 & 15214811 & 1379168 & 10.0 \\
\hline $\begin{array}{l}\text { Czech } \\
\text { Republic }\end{array}$ & 19938394026 & 20630977742 & 692583716 & 3.5 & 45982822 & 49001129 & 3018307 & 6.6 \\
\hline Germany & 25296438480 & 26011079070 & 714640590 & 2.8 & 126126787 & 134121574 & 7994787 & 6.3 \\
\hline Denmark & 16828217613 & 17119124818 & 290907205 & 1.7 & 51693391 & 52933792 & 1240401 & 2.4 \\
\hline Estonia & 8342255325 & 8739720519 & 397465194 & 4.8 & 14620118 & 15727413 & 1107295 & 7.6 \\
\hline Spain & 12457616698 & 12960785226 & 503168528 & 4.0 & 37012778 & 39625668 & 2612890 & 7.1 \\
\hline Finland & 7264303778 & 7425787944 & 161484166 & 2.2 & 22313274 & 23348004 & 1034730 & 4.6 \\
\hline France & 21340139207 & 21969251130 & 629111923 & 2.9 & 75318632 & 79932557 & 4613925 & 6.1 \\
\hline $\begin{array}{l}\text { Great } \\
\text { Britain }\end{array}$ & 20877669172 & 21701612987 & 823943815 & 3.9 & 137214818 & 150754969 & 13540151 & 9.9 \\
\hline Greece & 8285611768 & 8607768745 & 322156977 & 3.9 & 24007593 & 26641285 & 2633693 & 11.0 \\
\hline Hungary & 15602415319 & 16206957368 & 604542049 & 3.9 & 35820689 & 39580301 & 3759612 & 10.5 \\
\hline Ireland & 12339810863 & 12849431932 & 509621069 & 4.1 & 39205107 & 45265191 & 6060083 & 15.5 \\
\hline Italy & 16400279599 & 16704869130 & 304589531 & 1.9 & 54831327 & 56988139 & 2156811 & 3.9 \\
\hline Lithuania & 10339670520 & 10791419152 & 451748632 & 4.4 & 16655816 & 17761366 & 1105550 & 6.6 \\
\hline Latvia & 9437575889 & 9850524465 & 412948576 & 4.4 & 16000034 & 16933570 & 933536 & 5.8 \\
\hline Netherlands & 30994867043 & 31908098695 & 913231652 & 2.9 & 177052006 & 191124229 & 14072223 & 7.9 \\
\hline Poland & 15023988832 & 15710867944 & 686879112 & 4.6 & 32705754 & 36312091 & 3606337 & 11.0 \\
\hline Portugal & 10286171686 & 10898156421 & 611984735 & 5.9 & 26764606 & 30286673 & 3522067 & 13.2 \\
\hline Romania & 9941012460 & 10323248926 & 382236466 & 3.8 & 15459595 & 17378743 & 1919149 & 12.4 \\
\hline Sweden & 11017085336 & 11269415525 & 252330189 & 2.3 & 22549362 & 23818046 & 1268684 & 5.6 \\
\hline Slovenia & 18282717197 & 18717124982 & 434407785 & 2.4 & 38995446 & 41130649 & 2135203 & 5.5 \\
\hline Slovakia & 16405221064 & 17062336338 & 657115274 & 4.0 & 30723103 & 33510970 & 2787867 & 9.1 \\
\hline Average & 15802045259 & 16317924283 & 515879024 & 3.5 & 53626879 & 57492934 & 3866056 & 7.8 \\
\hline STD & 6691144859 & 6826831418 & 183784624 & 1.0 & 48846618 & 52025221 & 3578610 & 3.2 \\
\hline $\mathrm{CV}$ & 42.3 & 41.8 & 35.6 & 29.5 & 91.1 & 90.5 & 92.6 & 41.1 \\
\hline
\end{tabular}

\subsection{Detecting accessibility changes in the last decade due to road infrastructure improvements}

Between 2001 and 2012, the European road network underwent a number of changes. According to the Database of European roads, the kilometres of highway increased by $65 \%$, which in some cases was due to the upgrading of former main roads into highways. For this reason, the total number of kilometres of main roads in 2012 is slightly lower than in $2001(-2.8 \%)$, even though there has also been a process of upgrading from secondary to main roads.

The maps in Fig. 5 show the spatial distribution of the new highways (left) and main road (right) sections. In both cases there is a clear centre-to-periphery pattern, with greater changes in peripheral countries, particularly in the case of highways. It is also worth mentioning the potential impact of new and upgraded roads in Croatia and Bosnia-Herzegovina on south-eastern countries like Greece, Bulgaria and Romania.

In order to analyse the differences between 2001 and 2012, the proposed interaction model (formula (8)) was also calibrated for 2001. Table 5 shows the calibrated values obtained for 2001 and 2012. As expected, the border effect decreased significantly between 2001 and 2012 (from 6.6 to 2.8), showing the increasing consolidation of the single market and the accession of new countries. This change in the border effect might also be influenced by the enlargement of the Schengen Agreement, whose impact on reducing travel times is (partially) compensated by the Eurovignette. Because of the reduced border effect, the distance decay is now sharper, reflecting an increase in international trade over medium and long distances. At the same time, the lower the border effect, the greater the pressure of competing rivals.

Changes in the parameters are brought about by the interaction of many forces. Here we have investigated purely the role of the improved transport network respecting the current values and distribution of the market potential. To do this, it was necessary to fix all other variables. We therefore computed a new version of the market potential specification with current parameters and GDP figures (those of year 2012) and the travel time values as in 2001 (also back-dating the SMLR variable since the new road infrastructure changes this parameter). Table 6 (left) shows that peripheral countries with low accessibility in 2001 and high investment in road infrastructure between 2001 and 2012 experienced the highest market potential growth (Poland, Hungary, Romania, Bulgaria, Greece, Portugal and Ireland). Conversely, central countries with low investment in road infrastructure during this period experienced modest accessibility improvements, most of them probably due to spillover effects (see Gutiérrez et al., 2011), that is, the benefits a country receives from the infrastructures built in another country. For comparison, we include in Table 6 the results we obtained using the traditional market potential model 


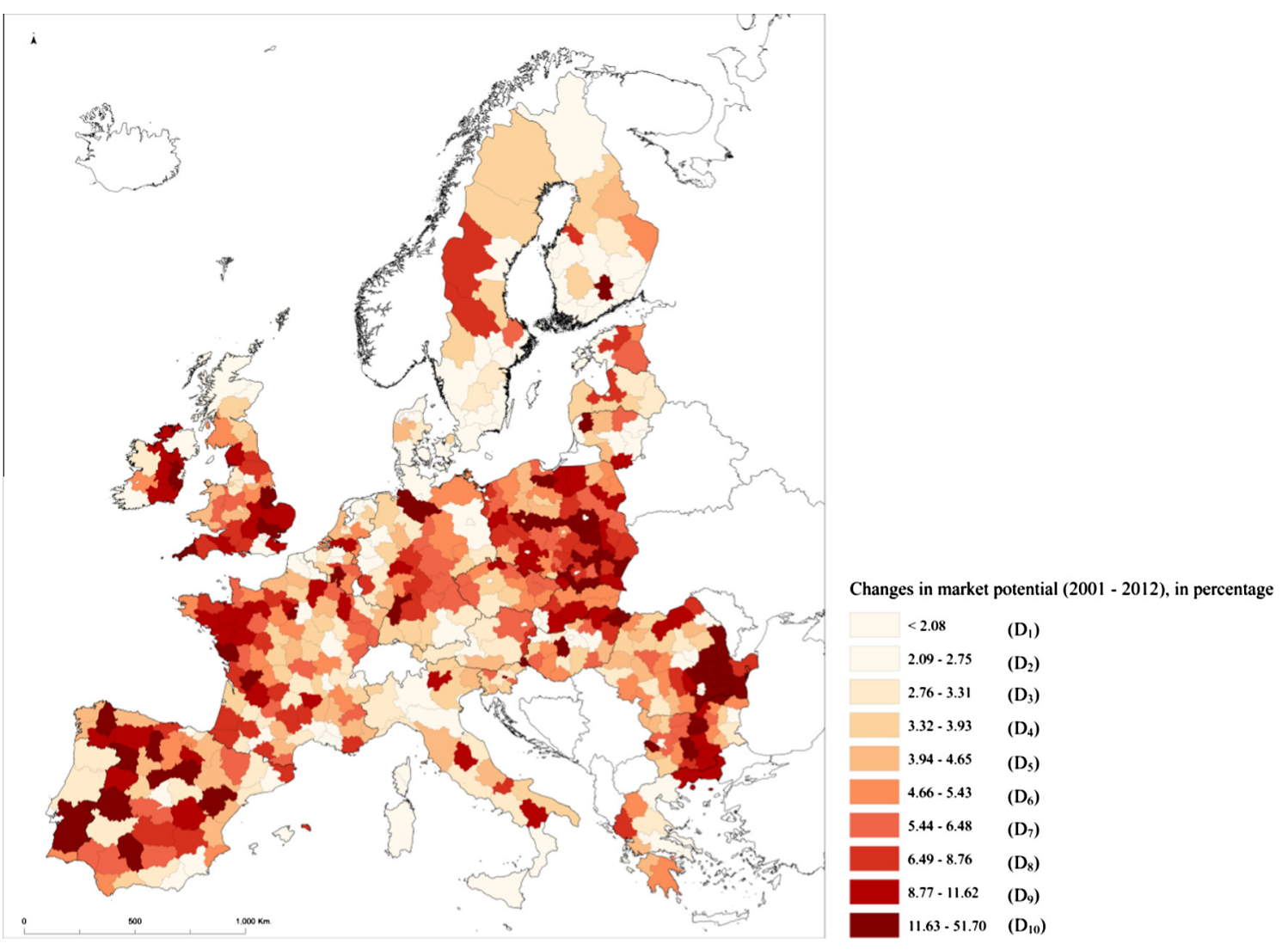

Fig. 6. Spatial distribution of the accessibility impact of investment in transport infrastructure between 2001 and 2012 , NUTs $2 / 3$.

(using a distance-decay parameter of 1 and not considering SMLR and borders). Accessibility changes due to new transport infrastructure are more intense in the proposed model, since it gives more weight to domestic relationships over short distances. More interestingly, the coefficient of variation is higher than when the traditional formulation is used (41.1 against 29.5), highlighting the benefits in countries where new infrastructure was built and smoothing spillover effects.

At regional level, the largest percentage increase in market potential corresponds to peripheral regions (see Fig. 6). The largest urban areas see the smallest increase in market potential. Instead of these areas, it is some regions close to capital cities and with better connections to them that are greater winners. This high difference in changes in market potential between big cities and their surrounding regions can be explained not only by the high self-potential of big cities but also by the asymmetrical nature of the effects of the new infrastructure when applying the potential indicator (see, for example, Gutiérrez, 2001).

\section{Conclusions and final remarks}

The market potential indicator has largely been used in transport planning to assess the accessibility impacts of transport infrastructure. However, the specification of the market potential model is typically very simple and ignores the impact both of competing rivals and the role of international borders, which leads to unrealistic results.

This paper presents a methodology for estimating the role of competing rivals when computing potential accessibility to markets. The so-called Spatial Multilateral Resistance (SMLR) is a new variable that captures the influence of all markets in the system over each particular bilateral relationship. This variable is based on fully observable and readily available data. It is easy to compute and gives accurate results. Its formulation permits its integration in the market potential formulation, which in turn improves the performance of the market potential model.

In addition to the role of competing rivals, international borders also have an impact on international trade. Our analysis indicates that EU countries trade 2.8 times less with other countries than within themselves, other things being equal. Although this effect is diminishing (6.6 times in 2001), borders still matter when talking about trade within the EU.

Similarly, the effect of distance needs to be calibrated in order to properly estimate the bilateral relationships, since slight changes in its value have a strong impact on the final market potential values. Our results indicate that reduction of the border effect highlights the role of distance and competing rivals. 
Table A.1

Export matrix (in percentage). Source: Own elaboration from WIOD.

\begin{tabular}{|c|c|c|c|c|c|c|c|c|c|c|c|c|c|c|c|c|c|c|c|c|c|c|c|c|c|}
\hline & AT & $\mathrm{BE}$ & BG & $\mathrm{CZ}$ & $\mathrm{DE}$ & DK & $\mathrm{EE}$ & ES & FI & FR & GB & GR & $\mathrm{HU}$ & IE & IT & LT & LV & NL & PL & PT & RO & SE & SI & SK & Total \\
\hline AT & 50.44 & 0.88 & 0.76 & 3.95 & 3.61 & 0.59 & 0.32 & 0.39 & 0.45 & 0.42 & 0.39 & 0.10 & 3.32 & 0.42 & 1.04 & 0.34 & 0.23 & 0.95 & 0.89 & 0.41 & 0.70 & 0.71 & 4.58 & 4.63 & 80.54 \\
\hline $\mathrm{BE}$ & 0.82 & 24.74 & 1.71 & 1.18 & 2.20 & 0.89 & 0.91 & 1.20 & 1.16 & 2.85 & 2.38 & 0.17 & 0.75 & 4.51 & 0.75 & 0.84 & 0.43 & 12.87 & 0.84 & 0.98 & 0.30 & 2.21 & 0.51 & 0.68 & 65.87 \\
\hline BG & 0.44 & 0.17 & 75.38 & 0.24 & 0.18 & 0.11 & 0.06 & 0.08 & 0.05 & 0.10 & 0.06 & 0.79 & 0.68 & 0.05 & 0.16 & 0.15 & 0.11 & 0.15 & 0.18 & 0.03 & 1.01 & 0.08 & 0.73 & 0.42 & 81.40 \\
\hline $\mathrm{CZ}$ & 2.41 & 0.85 & 0.46 & 47.59 & 1.98 & 0.85 & 0.55 & 0.37 & 0.32 & 0.42 & 0.40 & 0.09 & 2.35 & 0.68 & 0.50 & 0.51 & 0.38 & 0.78 & 2.77 & 0.31 & 0.46 & 0.51 & 1.96 & 8.67 & 76.14 \\
\hline $\mathrm{DE}$ & 23.73 & 19.23 & 4.76 & 22.46 & 61.29 & 13.77 & 5.39 & 4.96 & 6.85 & 8.03 & 8.45 & 1.47 & 19.62 & 11.52 & 6.22 & 7.34 & 5.49 & 22.31 & 13.86 & 4.84 & 5.29 & 8.12 & 20.29 & 16.66 & 321.96 \\
\hline DK & 0.33 & 0.97 & 0.19 & 0.43 & 0.97 & 43.85 & 1.96 & 0.19 & 1.42 & 0.26 & 1.23 & 0.09 & 0.45 & 0.75 & 0.25 & 1.66 & 1.76 & 1.54 & 0.81 & 0.17 & 0.09 & 5.05 & 0.79 & 0.40 & 65.59 \\
\hline EE & 0.03 & 0.05 & 0.01 & 0.04 & 0.05 & 0.11 & 44.27 & 0.01 & 0.62 & 0.01 & 0.05 & 0.00 & 0.06 & 0.04 & 0.02 & 1.66 & 3.13 & 0.05 & 0.14 & 0.01 & 0.01 & 0.24 & 0.08 & 0.02 & 50.71 \\
\hline ES & 1.37 & 3.01 & 1.14 & 1.57 & 2.35 & 2.24 & 0.38 & 72.72 & 1.18 & 3.52 & 2.60 & 0.50 & 2.23 & 2.73 & 2.63 & 0.87 & 0.59 & 3.11 & 1.43 & 9.23 & 0.72 & 1.48 & 1.08 & 2.76 & 121.43 \\
\hline FI & 0.32 & 0.76 & 0.07 & 0.37 & 0.60 & 2.12 & 15.95 & 0.16 & 71.42 & 0.21 & 0.38 & 0.14 & 0.18 & 0.27 & 0.18 & 1.23 & 2.43 & 1.00 & 0.39 & 0.20 & 0.05 & 4.35 & 0.26 & 0.20 & 103.25 \\
\hline FR & 3.05 & 15.35 & 1.88 & 3.95 & 6.90 & 3.55 & 1.83 & 7.09 & 1.95 & 72.09 & 5.34 & 0.55 & 3.85 & 5.66 & 4.68 & 4.92 & 1.02 & 6.97 & 3.23 & 4.82 & 1.94 & 3.54 & 6.31 & 4.73 & 175.21 \\
\hline GB & 2.21 & 9.29 & 0.66 & 3.35 & 4.41 & 9.86 & 1.57 & 2.58 & 2.69 & 3.32 & 65.22 & 0.50 & 4.14 & 13.08 & 2.04 & 2.59 & 2.06 & 9.52 & 3.54 & 2.08 & 0.89 & 4.61 & 1.72 & 2.72 & 154.66 \\
\hline GR & 0.33 & 0.83 & 2.74 & 0.20 & 0.45 & 0.62 & 0.05 & 0.39 & 0.19 & 0.33 & 0.33 & 92.91 & 0.30 & 0.23 & 0.64 & 0.10 & 0.07 & 0.72 & 0.17 & 0.14 & 0.33 & 0.23 & 0.52 & 0.27 & 103.06 \\
\hline $\mathrm{HU}$ & 2.77 & 0.61 & 0.37 & 1.50 & 1.22 & 0.36 & 0.15 & 0.16 & 0.25 & 0.31 & 0.28 & 0.06 & 47.20 & 0.27 & 0.38 & 0.24 & 0.15 & 0.72 & 1.29 & 0.12 & 1.35 & 0.44 & 3.01 & 4.86 & 68.06 \\
\hline IE & 0.12 & 0.50 & 0.02 & 0.15 & 0.28 & 0.61 & 0.06 & 0.14 & 0.12 & 0.24 & 2.99 & 0.03 & 0.12 & 52.43 & 0.09 & 0.22 & 1.20 & 0.77 & 0.21 & 0.11 & 0.03 & 0.23 & 0.05 & 0.07 & 60.81 \\
\hline IT & 5.40 & 6.02 & 4.53 & 2.85 & 4.57 & 2.54 & 1.71 & 3.86 & 1.28 & 3.97 & 2.43 & 1.39 & 3.61 & 2.40 & 76.86 & 1.48 & 0.77 & 6.41 & 3.09 & 1.53 & 3.39 & 2.01 & 8.96 & 4.37 & 155.43 \\
\hline LT & 0.06 & 0.12 & 0.05 & 0.11 & 0.10 & 0.33 & 4.18 & 0.04 & 0.33 & 0.03 & 0.04 & 0.01 & 0.08 & 0.03 & 0.05 & 59.24 & 7.31 & 0.17 & 0.72 & 0.01 & 0.01 & 0.28 & 0.11 & 0.13 & 73.53 \\
\hline LV & 0.05 & 0.07 & 0.04 & 0.06 & 0.06 & 0.22 & 5.50 & 0.02 & 0.33 & 0.02 & 0.02 & 0.00 & 0.10 & 0.01 & 0.03 & 6.10 & 66.88 & 0.08 & 0.24 & 0.01 & 0.01 & 0.13 & 0.11 & 0.10 & 80.20 \\
\hline NL & 0.79 & 11.74 & 0.29 & 1.33 & 2.92 & 2.05 & 1.25 & 1.01 & 2.00 & 1.36 & 4.34 & 0.19 & 0.95 & 1.87 & 0.58 & 2.94 & 0.73 & 27.20 & 1.26 & 0.97 & 0.47 & 2.34 & 0.73 & 0.82 & 70.15 \\
\hline PL & 1.73 & 1.50 & 0.84 & 3.45 & 2.51 & 2.53 & 1.69 & 0.60 & 1.35 & 0.79 & 0.83 & 0.37 & 2.77 & 0.66 & 1.00 & 4.41 & 1.46 & 1.55 & 61.85 & 0.39 & 0.72 & 1.62 & 2.25 & 4.65 & 101.52 \\
\hline PT & 0.18 & 0.55 & 0.17 & 0.20 & 0.47 & 0.31 & 0.04 & 3.25 & 0.09 & 0.43 & 0.31 & 0.06 & 0.25 & 0.39 & 0.33 & 0.17 & 0.02 & 0.66 & 0.14 & 72.97 & 0.07 & 0.28 & 0.14 & 0.16 & 81.64 \\
\hline RO & 1.15 & 0.42 & 3.44 & 0.68 & 0.55 & 0.43 & 0.11 & 0.22 & 0.12 & 0.31 & 0.24 & 0.36 & 3.84 & 0.20 & 0.63 & 0.20 & 0.20 & 0.38 & 0.74 & 0.16 & 81.63 & 0.13 & 1.44 & 1.14 & 98.71 \\
\hline SE & 0.81 & 2.05 & 0.14 & 0.89 & 1.58 & 11.77 & 11.85 & 0.36 & 5.69 & 0.71 & 1.52 & 0.09 & 0.95 & 1.57 & 0.41 & 2.64 & 3.45 & 1.82 & 1.38 & 0.40 & 0.17 & 61.24 & 0.69 & 1.74 & 113.90 \\
\hline SI & 0.83 & 0.11 & 0.25 & 0.26 & 0.21 & 0.06 & 0.05 & 0.09 & 0.06 & 0.09 & 0.05 & 0.07 & 0.46 & 0.05 & 0.35 & 0.03 & 0.02 & 0.10 & 0.15 & 0.03 & 0.11 & 0.06 & 42.84 & 0.36 & 46.71 \\
\hline \multirow[t]{2}{*}{ SK } & 0.63 & 0.18 & 0.12 & 3.18 & 0.53 & 0.23 & 0.17 & 0.09 & 0.09 & 0.18 & 0.11 & 0.05 & 1.75 & 0.18 & 0.18 & 0.12 & 0.12 & 0.16 & 0.68 & 0.08 & 0.25 & 0.13 & 0.86 & 39.45 & 49.53 \\
\hline & 100 & 100 & 100 & 100 & 100 & 100 & 100 & 100 & 100 & 100 & 100 & 100 & 100 & 100 & 100 & 100 & 100 & 100 & 100 & 100 & 100 & 100 & 100 & 100 & \\
\hline
\end{tabular}


Table A.2

Contribution of each country to each other market potential (in percentage). traditional model (without parameter calibration). Source: Own elaboration from WIOD. EUROSTAT. Database of European Roads 1957-2012 and GISCO.

\begin{tabular}{|c|c|c|c|c|c|c|c|c|c|c|c|c|c|c|c|c|c|c|c|c|c|c|c|c|c|}
\hline & AT & $\mathrm{BE}$ & BG & $\mathrm{CZ}$ & $\mathrm{DE}$ & DK & EE & ES & FI & FR & GB & GR & $\mathrm{HU}$ & IE & IT & LT & LV & NL & PL & PT & RO & SE & SI & SK & Total \\
\hline AT & 9.25 & 1.37 & 3.66 & 5.44 & 2.58 & 2.06 & 2.70 & 1.71 & 2.25 & 1.80 & 1.27 & 3.12 & 6.20 & 1.54 & 3.18 & 2.95 & 2.79 & 1.42 & 3.58 & 1.65 & 3.84 & 2.14 & 6.99 & 6.46 & 79.96 \\
\hline $\mathrm{BE}$ & 2.77 & 18.42 & 2.58 & 2.85 & 4.35 & 3.49 & 2.93 & 2.79 & 2.77 & 4.55 & 3.80 & 2.48 & 2.56 & 3.29 & 2.65 & 2.96 & 2.96 & 8.28 & 2.94 & 2.71 & 2.65 & 3.20 & 2.59 & 2.60 & 93.16 \\
\hline BG & 0.23 & 0.08 & 2.51 & 0.21 & 0.12 & 0.14 & 0.25 & 0.15 & 0.23 & 0.12 & 0.10 & 0.84 & 0.39 & 0.13 & 0.22 & 0.25 & 0.25 & 0.08 & 0.24 & 0.15 & 0.99 & 0.18 & 0.29 & 0.31 & 8.46 \\
\hline$C Z$ & 2.84 & 0.73 & 1.71 & 5.98 & 1.50 & 1.32 & 1.63 & 0.83 & 1.29 & 0.88 & 0.68 & 1.50 & 2.70 & 0.81 & 1.23 & 1.90 & 1.74 & 0.81 & 2.81 & 0.82 & 1.86 & 1.29 & 2.05 & 3.56 & 42.46 \\
\hline $\mathrm{DE}$ & 28.60 & 23.73 & 21.73 & 31.79 & 39.94 & 28.91 & 23.82 & 16.67 & 20.95 & 21.18 & 15.97 & 20.24 & 24.48 & 17.23 & 21.22 & 25.15 & 24.57 & 26.59 & 28.16 & 16.14 & 22.68 & 24.94 & 24.59 & 26.18 & 575.45 \\
\hline DK & 1.38 & 1.16 & 1.54 & 1.69 & 1.75 & 11.03 & 2.10 & 1.16 & 2.58 & 1.17 & 1.07 & 1.50 & 1.48 & 1.28 & 1.20 & 2.18 & 2.15 & 1.43 & 2.07 & 1.19 & 1.60 & 4.42 & 1.27 & 1.59 & 50.00 \\
\hline $\mathrm{EE}$ & 0.06 & 0.03 & 0.09 & 0.07 & 0.05 & 0.07 & 2.26 & 0.05 & 0.38 & 0.04 & 0.04 & 0.09 & 0.08 & 0.06 & 0.05 & 0.38 & 0.64 & 0.04 & 0.13 & 0.06 & 0.10 & 0.12 & 0.06 & 0.09 & 5.05 \\
\hline ES & 3.79 & 3.04 & 5.33 & 3.49 & 3.33 & 3.81 & 4.97 & 21.95 & 5.06 & 6.20 & 3.70 & 5.41 & 4.09 & 4.70 & 5.44 & 4.58 & 4.75 & 2.89 & 3.86 & 19.03 & 5.07 & 4.61 & 4.32 & 3.85 & 137.29 \\
\hline FI & 0.51 & 0.31 & 0.83 & 0.57 & 0.43 & 0.88 & 3.73 & 0.52 & 11.39 & 0.41 & 0.39 & 0.85 & 0.67 & 0.56 & 0.50 & 1.89 & 2.42 & 0.35 & 0.90 & 0.57 & 0.88 & 1.88 & 0.53 & 0.69 & 32.65 \\
\hline FR & 12.89 & 16.07 & 13.53 & 12.00 & 13.72 & 12.45 & 13.17 & 20.10 & 12.75 & 29.78 & 13.93 & 13.14 & 12.28 & 14.33 & 15.99 & 12.79 & 12.99 & 13.11 & 11.97 & 17.89 & 13.36 & 13.20 & 13.25 & 12.03 & 346.73 \\
\hline GB & 7.98 & 11.76 & 9.49 & 8.10 & 9.04 & 9.98 & 10.88 & 10.48 & 10.77 & 12.17 & 41.83 & 9.51 & 8.24 & 26.86 & 8.56 & 10.40 & 10.65 & 10.21 & 9.22 & 10.60 & 9.62 & 10.88 & 7.92 & 8.21 & 283.38 \\
\hline GR & 0.91 & 0.36 & 3.92 & 0.84 & 0.54 & 0.65 & 1.16 & 0.72 & 1.09 & 0.54 & 0.44 & 11.62 & 1.41 & 0.63 & 0.97 & 1.12 & 1.13 & 0.38 & 0.99 & 0.74 & 2.49 & 0.83 & 1.12 & 1.17 & 35.75 \\
\hline $\mathrm{HU}$ & 1.62 & 0.33 & 1.63 & 1.35 & 0.58 & 0.58 & 0.94 & 0.48 & 0.77 & 0.45 & 0.34 & 1.26 & 5.60 & 0.44 & 0.81 & 1.05 & 0.99 & 0.35 & 1.28 & 0.47 & 1.92 & 0.63 & 1.71 & 2.94 & 28.53 \\
\hline IE & 0.53 & 0.55 & 0.71 & 0.53 & 0.53 & 0.65 & 0.81 & 0.72 & 0.83 & 0.68 & 1.46 & 0.73 & 0.57 & 10.75 & 0.58 & 0.75 & 0.78 & 0.53 & 0.63 & 0.76 & 0.71 & 0.77 & 0.54 & 0.56 & 26.68 \\
\hline IT & 13.67 & 5.63 & 14.97 & 10.13 & 8.25 & 7.72 & 10.21 & 10.60 & 9.34 & 9.60 & 5.88 & 14.32 & 13.34 & 7.39 & 27.24 & 10.11 & 10.08 & 5.46 & 9.74 & 9.64 & 13.79 & 8.78 & 18.69 & 12.01 & 266.58 \\
\hline LT & 0.16 & 0.08 & 0.22 & 0.20 & 0.12 & 0.18 & 0.90 & 0.11 & 0.45 & 0.10 & 0.09 & 0.21 & 0.22 & 0.12 & 0.13 & 2.55 & 1.46 & 0.09 & 0.41 & 0.12 & 0.25 & 0.24 & 0.16 & 0.24 & 8.78 \\
\hline LV & 0.09 & 0.05 & 0.13 & 0.11 & 0.07 & 0.10 & 0.90 & 0.07 & 0.34 & 0.06 & 0.06 & 0.13 & 0.12 & 0.07 & 0.08 & 0.87 & 2.27 & 0.05 & 0.21 & 0.07 & 0.14 & 0.16 & 0.09 & 0.13 & 6.37 \\
\hline $\mathrm{NL}$ & 4.43 & 12.73 & 4.16 & 4.82 & 7.49 & 6.66 & 5.01 & 4.07 & 4.74 & 5.70 & 5.08 & 4.00 & 4.15 & 4.81 & 3.95 & 5.12 & 5.09 & 23.96 & 5.17 & 4.02 & 4.30 & 5.70 & 4.11 & 4.33 & 143.59 \\
\hline PL & 3.40 & 1.38 & 3.59 & 5.09 & 2.42 & 2.94 & 5.27 & 1.66 & 3.74 & 1.59 & 1.40 & 3.21 & 4.64 & 1.75 & 2.15 & 7.07 & 6.02 & 1.58 & 10.46 & 1.69 & 4.05 & 3.01 & 3.02 & 5.78 & 86.90 \\
\hline PT & 0.50 & 0.41 & 0.74 & 0.47 & 0.44 & 0.54 & 0.73 & 2.62 & 0.76 & 0.76 & 0.51 & 0.76 & 0.55 & 0.68 & 0.68 & 0.66 & 0.69 & 0.39 & 0.54 & 9.08 & 0.70 & 0.67 & 0.56 & 0.53 & 24.98 \\
\hline RO & 0.85 & 0.29 & 3.50 & 0.79 & 0.45 & 0.53 & 0.97 & 0.51 & 0.85 & 0.41 & 0.34 & 1.88 & 1.63 & 0.46 & 0.71 & 0.99 & 0.97 & 0.31 & 0.94 & 0.51 & 5.37 & 0.63 & 0.95 & 1.25 & 26.11 \\
\hline SE & 1.52 & 1.12 & 1.98 & 1.74 & 1.60 & 4.67 & 3.62 & 1.48 & 5.84 & 1.30 & 1.23 & 2.00 & 1.72 & 1.60 & 1.44 & 3.10 & 3.52 & 1.30 & 2.25 & 1.56 & 2.03 & 10.99 & 1.46 & 1.78 & 60.85 \\
\hline SI & 0.77 & 0.14 & 0.51 & 0.43 & 0.25 & 0.21 & 0.30 & 0.22 & 0.25 & 0.20 & 0.14 & 0.42 & 0.72 & 0.17 & 0.48 & 0.32 & 0.30 & 0.15 & 0.35 & 0.20 & 0.48 & 0.23 & 2.75 & 0.58 & 10.56 \\
\hline \multirow[t]{2}{*}{ SK } & 1.24 & 0.25 & 0.94 & 1.31 & 0.45 & 0.46 & 0.73 & 0.33 & 0.58 & 0.32 & 0.25 & 0.77 & 2.16 & 0.32 & 0.54 & 0.85 & 0.78 & 0.27 & 1.17 & 0.33 & 1.09 & 0.48 & 1.00 & 3.13 & 19.72 \\
\hline & 100 & 100 & 100 & 100 & 100 & 100 & 100 & 100 & 100 & 100 & 100 & 100 & 100 & 100 & 100 & 100 & 100 & 100 & 100 & 100 & 100 & 100 & 100 & 100 & \\
\hline
\end{tabular}


Table A.3

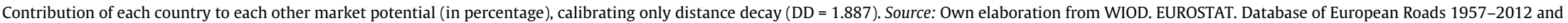
GISCO.

\begin{tabular}{|c|c|c|c|c|c|c|c|c|c|c|c|c|c|c|c|c|c|c|c|c|c|c|c|c|c|}
\hline & AT & $\mathrm{BE}$ & BG & $\mathrm{CZ}$ & $\mathrm{DE}$ & DK & $\mathrm{EE}$ & ES & FI & FR & GB & GR & $\mathrm{HU}$ & IE & IT & LT & LV & NL & PL & PT & RO & SE & SI & SK & Total \\
\hline AT & 23.90 & 0.45 & 4.30 & 8.54 & 2.22 & 1.26 & 2.22 & 1.02 & 1.38 & 1.21 & 0.47 & 2.64 & 10.30 & 0.63 & 3.43 & 2.78 & 2.42 & 0.49 & 4.08 & 0.79 & 4.81 & 1.57 & 13.57 & 11.75 & 3.96 \\
\hline $\mathrm{BE}$ & 2.04 & 50.58 & 1.85 & 2.09 & 4.91 & 2.83 & 2.15 & 2.14 & 1.70 & 5.76 & 3.08 & 1.42 & 1.61 & 2.17 & 2.02 & 2.32 & 2.24 & 11.42 & 2.32 & 1.68 & 1.98 & 2.78 & 1.73 & 1.75 & 12.71 \\
\hline BG & 0.14 & 0.01 & 12.98 & 0.11 & 0.04 & 0.05 & 0.16 & 0.06 & 0.11 & 0.04 & 0.02 & 1.37 & 0.35 & 0.04 & 0.14 & 0.17 & 0.16 & 0.01 & 0.15 & 0.05 & 2.31 & 0.09 & 0.20 & 0.23 & 0.28 \\
\hline $\mathrm{CZ}$ & 4.61 & 0.25 & 1.83 & 18.28 & 1.43 & 0.97 & 1.53 & 0.46 & 0.87 & 0.55 & 0.25 & 1.18 & 3.83 & 0.34 & 1.03 & 2.17 & 1.76 & 0.31 & 4.59 & 0.38 & 2.19 & 1.08 & 2.39 & 6.84 & 2.26 \\
\hline $\mathrm{DE}$ & 29.42 & 14.40 & 18.17 & 35.03 & 56.97 & 26.90 & 19.75 & 10.98 & 13.62 & 18.54 & 8.13 & 13.15 & 20.16 & 8.69 & 18.08 & 23.25 & 21.45 & 18.20 & 29.23 & 8.62 & 20.06 & 23.68 & 21.33 & 24.14 & 21.81 \\
\hline DK & 0.80 & 0.40 & 1.02 & 1.14 & 1.30 & 36.20 & 1.68 & 0.59 & 2.17 & 0.65 & 0.41 & 0.81 & 0.84 & 0.53 & 0.67 & 1.90 & 1.80 & 0.61 & 1.77 & 0.52 & 1.11 & 7.50 & 0.66 & 1.02 & 2.26 \\
\hline $\mathrm{EE}$ & 0.03 & 0.01 & 0.06 & 0.03 & 0.02 & 0.03 & 21.07 & 0.02 & 0.63 & 0.01 & 0.01 & 0.05 & 0.04 & 0.02 & 0.02 & 0.77 & 1.99 & 0.01 & 0.10 & 0.02 & 0.07 & 0.09 & 0.02 & 0.05 & 0.28 \\
\hline ES & 1.46 & 0.67 & 2.88 & 1.22 & 1.18 & 1.32 & 2.31 & 41.56 & 2.10 & 4.11 & 1.16 & 2.45 & 1.55 & 1.69 & 3.12 & 2.10 & 2.18 & 0.62 & 1.55 & 26.47 & 2.67 & 2.20 & 1.81 & 1.46 & 2.65 \\
\hline FI & 0.15 & 0.04 & 0.40 & 0.18 & 0.11 & 0.38 & 6.15 & 0.16 & 44.34 & 0.11 & 0.08 & 0.34 & 0.24 & 0.14 & 0.16 & 1.80 & 2.77 & 0.05 & 0.45 & 0.16 & 0.45 & 1.86 & 0.15 & 0.26 & 0.67 \\
\hline FR & 8.28 & 8.74 & 9.40 & 7.05 & 9.60 & 6.95 & 8.17 & 19.80 & 6.75 & 44.63 & 7.95 & 7.36 & 6.94 & 7.77 & 13.42 & 8.22 & 8.16 & 6.06 & 7.36 & 13.25 & 9.35 & 9.02 & 8.41 & 7.05 & 10.16 \\
\hline GB & 3.73 & 5.40 & 5.36 & 3.75 & 4.87 & 5.10 & 6.35 & 6.45 & 5.48 & 9.20 & 70.62 & 4.46 & 3.65 & 28.36 & 4.60 & 6.20 & 6.25 & 4.22 & 5.01 & 5.50 & 5.61 & 6.98 & 3.55 & 3.82 & 9.91 \\
\hline GR & 0.42 & 0.05 & 6.73 & 0.34 & 0.16 & 0.20 & 0.62 & 0.27 & 0.48 & 0.17 & 0.09 & 43.37 & 0.87 & 0.16 & 0.51 & 0.62 & 0.61 & 0.06 & 0.50 & 0.24 & 2.93 & 0.36 & 0.59 & 0.65 & 0.84 \\
\hline $\mathrm{HU}$ & 2.38 & 0.08 & 2.50 & 1.64 & 0.35 & 0.30 & 0.82 & 0.25 & 0.49 & 0.23 & 0.11 & 1.27 & 22.74 & 0.16 & 0.69 & 1.06 & 0.91 & 0.09 & 1.55 & 0.20 & 3.48 & 0.42 & 2.55 & 7.09 & 1.64 \\
\hline IE & 0.18 & 0.14 & 0.33 & 0.18 & 0.19 & 0.24 & 0.40 & 0.35 & 0.36 & 0.33 & 1.05 & 0.29 & 0.20 & 41.89 & 0.24 & 0.36 & 0.38 & 0.13 & 0.26 & 0.32 & 0.34 & 0.39 & 0.18 & 0.20 & 1.36 \\
\hline IT & 11.40 & 1.49 & 14.02 & 6.32 & 4.53 & 3.47 & 6.23 & 7.29 & 4.63 & 6.50 & 1.93 & 10.68 & 10.00 & 2.75 & 45.22 & 6.50 & 6.23 & 1.43 & 6.15 & 5.08 & 12.24 & 5.15 & 19.83 & 8.65 & 6.47 \\
\hline LT & 0.09 & 0.02 & 0.16 & 0.12 & 0.05 & 0.09 & 2.07 & 0.05 & 0.49 & 0.04 & 0.02 & 0.12 & 0.14 & 0.04 & 0.06 & 15.82 & 5.30 & 0.02 & 0.50 & 0.04 & 0.20 & 0.19 & 0.08 & 0.18 & 0.39 \\
\hline LV & 0.04 & 0.01 & 0.09 & 0.06 & 0.03 & 0.05 & 3.03 & 0.03 & 0.43 & 0.02 & 0.01 & 0.07 & 0.07 & 0.02 & 0.03 & 3.02 & 17.83 & 0.01 & 0.20 & 0.02 & 0.11 & 0.13 & 0.04 & 0.08 & 0.34 \\
\hline $\mathrm{NL}$ & 3.21 & 16.41 & 2.96 & 3.68 & 8.92 & 6.21 & 3.84 & 2.84 & 3.04 & 5.74 & 3.46 & 2.28 & 2.61 & 2.89 & 2.80 & 4.26 & 4.06 & 55.18 & 4.40 & 2.31 & 3.21 & 5.39 & 2.69 & 2.99 & 14.53 \\
\hline PL & 2.99 & 0.38 & 3.43 & 6.25 & 1.62 & 2.03 & 6.48 & 0.80 & 2.97 & 0.79 & 0.46 & 2.30 & 4.92 & 0.66 & 1.36 & 11.98 & 8.52 & 0.50 & 25.48 & 0.69 & 4.39 & 2.48 & 2.30 & 7.88 & 2.79 \\
\hline PT & 0.16 & 0.07 & 0.34 & 0.14 & 0.13 & 0.16 & 0.31 & 3.74 & 0.29 & 0.39 & 0.14 & 0.30 & 0.17 & 0.22 & 0.31 & 0.27 & 0.29 & 0.07 & 0.19 & 32.65 & 0.32 & 0.29 & 0.19 & 0.17 & 0.79 \\
\hline RO & 0.55 & 0.05 & 8.22 & 0.46 & 0.17 & 0.20 & 0.67 & 0.21 & 0.46 & 0.16 & 0.08 & 2.11 & 1.72 & 0.13 & 0.42 & 0.74 & 0.69 & 0.06 & 0.68 & 0.18 & 18.77 & 0.33 & 0.66 & 1.11 & 0.67 \\
\hline $\mathrm{SE}$ & 0.63 & 0.25 & 1.08 & 0.80 & 0.71 & 4.70 & 3.08 & 0.62 & 6.66 & 0.53 & 0.35 & 0.91 & 0.73 & 0.54 & 0.62 & 2.44 & 2.99 & 0.33 & 1.35 & 0.57 & 1.15 & 27.51 & 0.57 & 0.83 & 1.24 \\
\hline SI & 1.43 & 0.04 & 0.68 & 0.47 & 0.17 & 0.11 & 0.23 & 0.13 & 0.15 & 0.13 & 0.05 & 0.39 & 1.16 & 0.07 & 0.63 & 0.27 & 0.24 & 0.04 & 0.33 & 0.10 & 0.61 & 0.15 & 15.24 & 0.80 & 0.92 \\
\hline \multirow[t]{2}{*}{ SK } & 1.98 & 0.07 & 1.21 & 2.13 & 0.31 & 0.27 & 0.69 & 0.17 & 0.39 & 0.17 & 0.08 & 0.69 & 5.16 & 0.12 & 0.44 & 0.97 & 0.79 & 0.08 & 1.81 & 0.14 & 1.63 & 0.35 & 1.28 & 11.01 & 1.06 \\
\hline & 100 & 100 & 100 & 100 & 100 & 100 & 100 & 100 & 100 & 100 & 100 & 100 & 100 & 100 & 100 & 100 & 100 & 100 & 100 & 100 & 100 & 100 & 100 & 100 & \\
\hline
\end{tabular}


Table A.4

Contribution of each country to each other market potential (in percentage), proposed model (DD $=1.830$, SMLR $=0.809, \mathrm{BE}=2.801$ ). Source: Own elaboration from WIOD. EUROSTAT. Database of European Roads $1957-2012$ and GISCO.

\begin{tabular}{|c|c|c|c|c|c|c|c|c|c|c|c|c|c|c|c|c|c|c|c|c|c|c|c|c|c|}
\hline & AT & $\mathrm{BE}$ & BG & $\mathrm{CZ}$ & $\mathrm{DE}$ & DK & $\mathrm{EE}$ & ES & FI & FR & GB & GR & $\mathrm{HU}$ & IE & IT & LT & LV & $\mathrm{NL}$ & PL & PT & RO & SE & SI & SK & Total \\
\hline AT & 46.77 & 0.33 & 2.64 & 6.50 & 1.19 & 0.71 & 1.14 & 0.42 & 0.41 & 0.64 & 0.17 & 0.86 & 6.51 & 0.29 & 1.56 & 1.75 & 1.41 & 0.32 & 2.50 & 0.36 & 2.69 & 0.80 & 10.09 & 9.08 & 99.16 \\
\hline $\mathrm{BE}$ & 0.96 & 69.65 & 0.78 & 1.10 & 1.65 & 1.06 & 0.75 & 0.57 & 0.34 & 2.04 & 0.73 & 0.32 & 0.72 & 0.65 & 0.59 & 0.99 & 0.88 & 4.90 & 0.96 & 0.50 & 0.76 & 0.93 & 0.92 & 0.96 & 93.70 \\
\hline BG & 0.18 & 0.02 & 36.94 & 0.16 & 0.04 & 0.05 & 0.15 & 0.05 & 0.06 & 0.04 & 0.01 & 0.78 & 0.41 & 0.03 & 0.12 & 0.19 & 0.17 & 0.02 & 0.17 & 0.05 & 2.28 & 0.08 & 0.29 & 0.34 & 42.62 \\
\hline CZ & 3.19 & 0.18 & 1.13 & 38.17 & 0.79 & 0.54 & 0.78 & 0.19 & 0.26 & 0.29 & 0.09 & 0.38 & 2.43 & 0.15 & 0.46 & 1.34 & 1.01 & 0.20 & 2.77 & 0.17 & 1.23 & 0.54 & 1.82 & 5.24 & 63.34 \\
\hline $\mathrm{DE}$ & 16.97 & 8.45 & 9.39 & 22.25 & 78.84 & 12.33 & 8.39 & 3.66 & 3.33 & 8.11 & 2.40 & 3.59 & 10.90 & 3.27 & 6.57 & 12.08 & 10.27 & 9.61 & 14.72 & 3.21 & 9.44 & 9.72 & 13.72 & 15.97 & 297.19 \\
\hline DK & 0.67 & 0.34 & 0.75 & 1.05 & 0.82 & 65.16 & 1.00 & 0.28 & 0.73 & 0.40 & 0.17 & 0.31 & 0.65 & 0.29 & 0.35 & 1.39 & 1.21 & 0.46 & 1.27 & 0.28 & 0.75 & 4.27 & 0.62 & 0.97 & 84.19 \\
\hline EE & 0.04 & 0.01 & 0.07 & 0.05 & 0.02 & 0.04 & 52.83 & 0.02 & 0.36 & 0.02 & 0.01 & 0.03 & 0.05 & 0.01 & 0.02 & 0.93 & 2.13 & 0.01 & 0.13 & 0.02 & 0.08 & 0.09 & 0.04 & 0.08 & 57.07 \\
\hline ES & 1.56 & 0.73 & 2.69 & 1.46 & 0.86 & 1.13 & 1.79 & 75.75 & 0.93 & 3.42 & 0.63 & 1.21 & 1.55 & 1.14 & 2.09 & 2.00 & 1.91 & 0.60 & 1.45 & 16.58 & 2.29 & 1.66 & 2.14 & 1.79 & 127.34 \\
\hline FI & 0.26 & 0.07 & 0.59 & 0.34 & 0.14 & 0.51 & 6.91 & 0.16 & 81.95 & 0.14 & 0.07 & 0.27 & 0.37 & 0.15 & 0.17 & 2.58 & 3.60 & 0.08 & 0.66 & 0.17 & 0.60 & 2.17 & 0.29 & 0.50 & 102.76 \\
\hline FR & 5.61 & 5.93 & 5.63 & 5.32 & 4.57 & 3.75 & 4.05 & 7.55 & 1.91 & 71.50 & 2.75 & 2.33 & 4.40 & 3.34 & 5.66 & 5.01 & 4.57 & 3.71 & 4.36 & 5.55 & 5.12 & 4.32 & 6.32 & 5.50 & 178.78 \\
\hline GB & 2.59 & 3.72 & 3.29 & 2.89 & 2.26 & 2.79 & 3.19 & 2.51 & 1.57 & 4.71 & 89.88 & 1.44 & 2.37 & 11.89 & 1.95 & 3.83 & 3.55 & 2.61 & 3.02 & 2.38 & 3.14 & 3.39 & 2.75 & 3.05 & 164.79 \\
\hline GR & 0.62 & 0.08 & 8.18 & 0.57 & 0.17 & 0.24 & 0.67 & 0.23 & 0.30 & 0.19 & 0.07 & 79.84 & 1.18 & 0.15 & 0.49 & 0.81 & 0.73 & 0.08 & 0.64 & 0.23 & 3.35 & 0.38 & 0.95 & 1.09 & 101.24 \\
\hline $\mathrm{HU}$ & 2.03 & 0.07 & 1.82 & 1.53 & 0.22 & 0.21 & 0.51 & 0.13 & 0.18 & 0.15 & 0.05 & 0.50 & 47.55 & 0.09 & 0.39 & 0.81 & 0.63 & 0.07 & 1.16 & 0.11 & 2.32 & 0.26 & 2.33 & 6.56 & 69.67 \\
\hline IE & 0.20 & 0.15 & 0.32 & 0.22 & 0.14 & 0.21 & 0.31 & 0.21 & 0.16 & 0.27 & 0.64 & 0.15 & 0.20 & 74.90 & 0.16 & 0.35 & 0.33 & 0.13 & 0.25 & 0.21 & 0.30 & 0.30 & 0.22 & 0.25 & 80.56 \\
\hline IT & 9.59 & 1.30 & 10.30 & 5.95 & 2.74 & 2.38 & 3.86 & 3.53 & 1.65 & 4.22 & 0.83 & 4.15 & 7.80 & 1.51 & 76.13 & 4.95 & 4.36 & 1.12 & 4.56 & 2.72 & 8.26 & 3.12 & 18.06 & 8.33 & 191.40 \\
\hline LT & 0.10 & 0.02 & 0.17 & 0.17 & 0.05 & 0.09 & 1.68 & 0.03 & 0.24 & 0.03 & 0.02 & 0.07 & 0.16 & 0.03 & 0.05 & 42.35 & 4.74 & 0.02 & 0.53 & 0.03 & 0.19 & 0.16 & 0.11 & 0.24 & 51.29 \\
\hline LV & 0.06 & 0.01 & 0.10 & 0.08 & 0.03 & 0.05 & 2.59 & 0.02 & 0.23 & 0.02 & 0.01 & 0.04 & 0.08 & 0.02 & 0.03 & 3.19 & 46.38 & 0.01 & 0.23 & 0.02 & 0.11 & 0.12 & 0.06 & 0.12 & 53.63 \\
\hline NL & 1.59 & 8.04 & 1.31 & 2.02 & 3.21 & 2.41 & 1.39 & 0.79 & 0.63 & 2.10 & 0.86 & 0.53 & 1.22 & 0.91 & 0.85 & 1.89 & 1.66 & 75.04 & 1.89 & 0.73 & 1.30 & 1.87 & 1.49 & 1.70 & 115.41 \\
\hline PL & 2.64 & 0.35 & 2.65 & 5.99 & 1.09 & 1.43 & 4.03 & 0.41 & 1.08 & 0.53 & 0.21 & 0.94 & 3.96 & 0.38 & 0.77 & 9.02 & 5.95 & 0.41 & 54.87 & 0.39 & 3.08 & 1.55 & 2.24 & 7.69 & 111.68 \\
\hline PT & 0.20 & 0.09 & 0.37 & 0.20 & 0.11 & 0.16 & 0.28 & 2.77 & 0.15 & 0.37 & 0.09 & 0.17 & 0.20 & 0.17 & 0.24 & 0.30 & 0.29 & 0.08 & 0.21 & 65.59 & 0.32 & 0.25 & 0.26 & 0.24 & 73.12 \\
\hline RO & 0.70 & 0.07 & 8.46 & 0.65 & 0.16 & 0.20 & 0.61 & 0.16 & 0.24 & 0.15 & 0.05 & 1.19 & 1.95 & 0.11 & 0.35 & 0.83 & 0.71 & 0.07 & 0.75 & 0.15 & 49.88 & 0.30 & 0.91 & 1.56 & 70.18 \\
\hline SE & 0.76 & 0.30 & 1.13 & 1.05 & 0.62 & 4.31 & 2.57 & 0.42 & 3.12 & 0.47 & 0.22 & 0.50 & 0.81 & 0.41 & 0.46 & 2.52 & 2.83 & 0.36 & 1.39 & 0.43 & 1.10 & 63.44 & 0.75 & 1.13 & 91.12 \\
\hline SI & 1.08 & 0.03 & 0.44 & 0.39 & 0.10 & 0.07 & 0.13 & 0.06 & 0.05 & 0.07 & 0.02 & 0.14 & 0.79 & 0.03 & 0.32 & 0.18 & 0.15 & 0.03 & 0.22 & 0.05 & 0.37 & 0.08 & 32.48 & 0.68 & 37.95 \\
\hline \multirow[t]{2}{*}{ SK } & 1.61 & 0.06 & 0.86 & 1.89 & 0.19 & 0.18 & 0.41 & 0.08 & 0.13 & 0.11 & 0.03 & 0.26 & 3.74 & 0.06 & 0.23 & 0.70 & 0.53 & 0.06 & 1.28 & 0.08 & 1.05 & 0.21 & 1.13 & 26.93 & 41.81 \\
\hline & 100 & 100 & 100 & 100 & 100 & 100 & 100 & 100 & 100 & 100 & 100 & 100 & 100 & 100 & 100 & 100 & 100 & 100 & 100 & 100 & 100 & 100 & 100 & 100 & \\
\hline
\end{tabular}


This paper proves that calibrating the distance-decay parameter and introducing SMLR and border effects into the market potential formula leads to more realistic results, highlighting differences between and within countries. When the new accessibility formulation is used, peripheral, border and less populated regions tend to record particularly low market potential values, while the accessibility of central, non-border and urban regions tends to be enhanced. The resulting market potential values are lower than estimations made with traditional formulations. Calibrating distance decay and introducing the border effect diminishes market potential values in all cases, while integration of the role of competing rivals compensates the market potential values between central markets (subject to more competition) and peripheral areas (where close neighbours find few competing rivals).

The proposed market potential model has been tested for assessing the accessibility impacts of improvements in road transport infrastructure in the European Union. According to the Database of European Roads (Stelder, 2013), which to our knowledge is the only open-source historical Europe-wide seamless road database, between 2001 and 2012 a process of upgrading from secondary to main roads took place, as well as the construction of new highways. The use of this data to test our methodology shows the impact of transport infrastructure on market potential values. In general terms, the construction of new roads has favoured peripheral regions. It has been proved that our model provides a more realistic and contrasted picture of changes in accessibility than the traditional one, highlighting the benefits in countries where new infrastructure has been built and smoothing spillover effects. Further research with a new methodological approach could accommodate the use of country-specific border effect and distance decay parameters, which will increase the accuracy of the model.

\title{
Acknowledgements
}

The authors gratefully acknowledge funding from the Spanish Ministerio de Economía y Competitividad (Project SPILLTRANS, TRA2011-27095 and post-doctoral fellowship FPDI-2013-17001). They would especially like to thank Dirk Stelder for providing public access to the Database of European Roads 1957-2012 as well as the anonymous reviewers for their useful suggestions.

\section{Appendix A. Tables used for correlations in Table 4 of the manuscript}

\author{
See Tables A.1-A.4.
}

\section{References}

Anderson, J.E., van Wincoop, E., 2001. Gravity with Gravitas: A Solution to the Border Puzzle. Natl. Bur. Econ. Res. Work. Pap. Ser. w8079.

Anderson, J.E., van Wincoop, E., 2003. Gravity with gravitas: a solution to the border puzzle. Am. Econ. Rev. 93 (1), $170-192$.

Anderson, J.E., van Wincoop, E., 2004. Trade costs. J. Econ. Lit. 42 (3), 691-751.

Bacaria-Colom, J., Osorio-Caballero, M.I., Artal-Tur, A., 2013. Evaluación del Acuerdo de Libre Comercio México-Unión Europea mediante un modelo gravitacional. Econ. Mex. Cierre de (I), 143-163.

Behncke, N., 2013. Assessing the Impact of European Integration on Sectoral Trade in Services. FIW Work. Pap. $109,27$.

Behrens, K., Ertur, C., Koch, W., 2012. "Dual” gravity: using spatial econometrics to control for multilateral resistance. J. Appl. Econ. 27 (5), $773-794$.

Bergstrand, J.H., 1985. The gravity equation in international trade: some microeconomic foundations and empirical evidence. Rev. Econ. Stat. 67 (3), $474-$ 481.

Bruinsma, F., Rietveld, P., 1998. The accessibility of European cities: theoretical framework and comparison of approaches. Environ. Plann. A 30 (3), 499521.

Bruyne, K. De, Magerman, G., Hove, J. Van, 2013. Revealed multilateral trade resistance in gravity models: a network approach. In: Proceedings of the ETSG Fifteenth Annual Conference, Birmingham.

Bussière, M., Fidrmuc, J., Schnatz, B., 2005. Trade Integration of Central and Eastern European Countries: Lessons from a Gravity Model. ECB Work. Pap. Ser. 0545.

Chen, N., 2004. Intra-national versus international trade in the European Union: why do national borders matter? J. Int. Econ. 63 (1), $93-118$.

Commission, E., 2006. Statistics on the Trading of Goods - User Guide.

Condeço-Melhorado, A., Gutiérrez, J., García-Palomares, J.C., 2011. Spatial impacts of road pricing: accessibility, regional spillovers and territorial cohesion. Transp. Res. Part A: Policy Pract. 45 (3), 185-203.

Condeço-Melhorado, A., Puebla, J.G., Palomares, J.C.G., 2013. Influence of distance decay on the measurement of spillover effects of transport infrastructure: a sensitivity analysis. GeoFocus (Artículos) 13 (1), 22-47.

DAF, n.d. The Contribution of Road Transport to a Cleaner Environment. DAF in Action Magazine.

Dundon-Smith, D.M., Gibb, R.A., 1994. The channel tunnel and regional economic development. J. Transp. Geogr. 2, $178-189$.

Egger, P., Larch, M., 2011. An assessment of the Europe agreements' effects on bilateral trade, GDP, and welfare. Eur. Econ. Rev. 55 (2), $263-279$.

ESPON, 2006. ESPON 3.4.3: The Modifiable Areas Unit Problem. Final Report.

ESPON, 2007. Update of Selected Potential Accessibility Indicators. Final Report, February 2007.

ESPON, 2015. TRACC Transport Accessibility at Regional/Local Scale and Patterns in Europe. Applied Research 2013/1/10. Final Report, Version 06/02/2015.

Feenstra, R., 2004. Advanced International Trade: Theory and Evidence. Princeton University Press, New Jersey.

Geurs, K.T., van Wee, B., 2004. Accessibility evaluation of land-use and transport strategies: review and research directions. J. Transp. Geogr. 12 (2), 127140.

Gutiérrez, J., 2001. Location, economic potential and daily accessibility: an analysis of the accessibility impact of the high-speed line Madrid-BarcelonaFrench border. J. Transp. Geogr. 9 (4), 229-242.

Gutiérrez, J., Condeço-Melhorado, A., López, E., Monzón, A., 2011. Evaluating the European added value of TEN-T projects: a methodological proposal based on spatial spillovers, accessibility and GIS. J. Transp. Geogr. 19 (4), 840-850.

Hansen, W.G., 1959. How accessibility shapes land use. J. Am. Inst. Plann. 25 (2), 73-76.

Harris, C.D., 1954. The market as a factor in the localization of industry in the United States. Ann. Assoc. Am. Geogr. 44 (4), $315-348$. 
Head, K., Mayer, T., 2000. Non-Europe: the magnitude and causes of market fragmentation in the EU. Rev. World Econ. (Weltwirtsch. Arch.) 136 (2), 284314.

Head, K., Mayer, T., 2002. Illusory Border Effects, Distance Mismeasurement Inflates Estimates of Home Bias in Trade. Centre d'études prospectives et d'informations internationales, Paris.

Head, K., Mayer, T., 2004. Market potential and the location of Japanese investment in the European Union. Rev. Econ. Stat. 86 (4), $959-972$.

Head, K., Mayer, T., 2014. Gravity equations: workhorse, toolkit, and cookbook. In: Gopinath, G., Helpman, E., Rogoff, K. (Eds.), Handbook of International Economics, vol. 4. Elsevier Science, pp. 131-195.

Helliwell, J.F., 2002. Measuring the width of national borders. Rev. Int. Econ. 10 (3), 517.

Helliwell, J.F., Verdier, G., 2001. Measuring internal trade distances: a new method applied to estimate provincial border effects in Canada. Can. J. Econ./Rev. Can. d'Economique 34 (4), 1024-1041.

Hillberry, R., Hummels, D., 2003. Intranational home bias: some explanations. Rev. Econ. Stat. 85 (4), 1089-1092.

Holl, A., 2007. In: Coto-MillÃ n, P., Inglada, V. (Eds.), Transport Network Development and the Location of Economic Activity. Physica-Verlag HD, pp. 341361.

Holl, A., 2011. Mejoras de accesibilidad viaria: un estudio retrospectivo para la España peninsular. Papeles Geogr. 53-54, 171-183.

Huber, P., Pfaffermayr, M., Wolfmayr, Y., 2006. Market potential and border effects in Europe. In: ERSA Conference Papers.

Keeble, D., Offord, J., Walker, S., 1988. Peripheral Regions in a Community of Twelve Member States. Office for Official Publications of the European Communities.

Krugman, P., 1992. A Dynamic Spatial Model. Natl. Bur. Econ. Res. Work. Pap. Ser. No. 4219.

Lopez, E., 2005. Measuring regional cohesion effects of large-scale transport infrastructure investments - an accessibility approach. In: ERSA Conference Papers.

López, E., Monzón, A., Ortega, E., Quintana, S.M., 2009. Assessment of cross-border spillover effects of national transport infrastructure plans: an accessibility approach. Transp. Rev. 29 (4), 515-536.

Martin, J., Garcia-Palomares, J., Gutierrez, J., Roman, C., 2010. Efficiency and equity of orbital motorways in Madrid. J. Transp. Land Use 3 (1).

Mayer, T., Zignago, S., 2011. Notes on CEPII's Distances Measures: The GeoDist Database (No. 2011-25).

McCallum, J., 1995. National borders matter: Canada-U.S. regional trade patterns. Am. Econ. Rev. Am. Econ. Assoc. 85 (3), $615-623$.

Minondo, A., 2005. Comercio y fronteras en la Europa "sin fronteras". Bol. Econ. ICE 2841, 15-25.

Minondo, A., 2007. The disappearance of the border barrier in some European Union countries' bilateral trade. Appl. Econ. 39 (1-3), 119-124.

Nitsch, V., 2000. National borders and international trade: evidence from the European Union. Can. J. Econ./Rev. Can. d'Economique 33 (4), $1091-1105$.

ONS, 2009. United Kingdom Balance of Payments. The Pink Book.

Reggiani, A., Bucci, P., 2008. Accessibility and impedance forms: empirical applications to the german commuting network. In: NARSC Conference, pp. 1922.

Reggiani, A., Bucci, P., Russo, G., 2011. Accessibility and impedance forms: empirical applications to the german commuting network. Int. Reg. Sci. Rev. 34 (2), 230-252.

Rich, D.C., 1978. Population potential, potential transportation cost and industrial location. Area, 222-226.

Rietveld, P., Bruinsma, F., 1998. Is Transport Infrastructure Effective? Transport Infrastructure and Accessibility: Impacts on the Space Economy. Springer, Berlin Heidelberg, Berlin.

Rosik, P., Stępniak, M., Komornicki, T., 2015. The decade of the big push to roads in Poland: impact on improvement in accessibility and territorial cohesion from a policy perspective. Transp. Policy 37, 134-146.

Salas-Olmedo, M.H., Condeço-Melhorado, A., Gutiérrez, J., 2014. Border effect and market potential: the case of the European Union. In: Condeço-Melhorado, A., Reggiani, A., Gutiérrez, J. (Eds.), Accessibility and Spatial Interaction. Edward Elgar, Cheltemham, UK, pp. 133-155.

Schürmann, C., Talaat, A., 2002. The European peripherality index. In: 42nd Congress of the European Regional Science Association (ERSA), Dortmund, pp. $27-31$.

Serlenga, L., Shin, Y., 2013. The Euro Effect on Intra-EU Trade: Evidence from the Cross Sectionally Dependent Panel Gravity Models. Unpubl. mimeo, pp. 130.

Spence, N., Linneker, B., 1994. Evolution of the motorway network and changing levels of accessibility in Great Britain. J. Transp. Geogr. 2 (4), $247-264$.

Spiekermann, K., Neubauer, J., 2002. European Accessibility and Peripherality: Concepts, Models and Indicators. Nord. Work. Pap. (2002:9).

Spiekermann, K., Wegener, M., 2006. Accessibility and spatial development in Europe. Sci. Reg. 5 (2), 15-46.

Stelder, D., 2013. Changes in Road Infrastructure and Accessibility in Europe since 1960. Final Report Revision and Additions, September, 2013.

Stelder, D., 2014. Regional Accessibility Trends in Europe: Road Infrastructure, 1957-2012. Reg. Stud. (ahead-of-print), pp. 1-13.

Stepniak, M., Rosik, P., 2013. Accessibility improvement, territorial cohesion and spillovers: a multidimensional evaluation of two motorway sections in Poland. J. Transp. Geogr. 31, 154-163.

Tagai, G., Pénzes, J., Molnar, E., 2008. Methods of the analysis of integration effect on border areas - the case of Hungary. Eurolimes 6, 150-159.

Timmer, M., Dietzenbacher, E., Bart, L., Stehrer, R., de Vries, G.J., 2015. An illustrated user guide to the world input-output database: the case of global automotive production. Rev. Int. Econ.

Wegener, M., 1995. Accessibility and development impacts. In: Banister, D. (Ed.), Transport and Urban Development. E\&FN Spon, London, pp. 157-161.

Wegener, M., Bökemann, D., 1998. The SASI Model: Model Structure. SASI Deliv. D 8.

Wei, S.-J., 1996. Intra-National versus International Trade: How Stubborn are Nations in Global Integration? National Bureau of Economic Research Inc.

Wolf, H.C., 1997. Patterns of Intra- and Inter-State Trade. Natl. Bur. Econ. Res. Work. Pap. Ser. 5939.

Wolf, H.C., 2000. Intranational home bias in trade. Rev. Econ. Stat. 82 (4), 555-563. 